\title{
Trivium
}

Revue franco-allemande de sciences humaines et sociales - Deutsch-französische Zeitschrift für Geistesund Sozialwissenschaften

32 | 2021

Institutions

\section{Die rechtliche Institution der Natur}

Bemerkungen über die Kasuistik des Naturrechts im antiken Rom

\section{Yan Thomas}

Traducteur : Nikolaus Gramm

\section{OpenEdition}

\section{Journals}

Édition électronique

URL : http://journals.openedition.org/trivium/7462

DOI : $10.4000 /$ trivium.7462

ISBN : 1963-1820

ISSN : 1963-1820

\section{Éditeur}

Les éditions de la Maison des sciences de l'Homme

Référence électronique

Yan Thomas, "Die rechtliche Institution der Natur", Trivium [Online], 32 | 2021, online erschienen am 28 Dezember 2020, abgerufen am 19 März 2021. URL: http://journals.openedition.org/trivium/7462 ; DOI: https://doi.org/10.4000/trivium.7462

Ce document a été généré automatiquement le 19 mars 2021.

\section{(c) (i) (9)}

Les contenus des la revue Trivium sont mis à disposition selon les termes de la Licence Creative Commons Attribution - Pas d'Utilisation Commerciale - Pas de Modification 4.0 International. 


\title{
Die rechtliche Institution der Natur
}

Bemerkungen über die Kasuistik des Naturrechts im antiken Rom

\author{
Yan Thomas
}

Traduction : Nikolaus Gramm

\section{NOTE DE L'ÉDITEUR}

\section{Originalausgabe | édition originale}

"L'institution juridique de la nature (remarques sur la casuistique du droit naturel à Rome) «, Revue d'histoire des facultés de droit et de la science juridique, Nr. 6, 1988, S. 27-48; neu abgedruckt in: Y. Thomas / P. Napoli (Hg.): Les opérations du droit, Paris: EHESS / Seuil / Gallimard, 2011, S. 21-40.

Wir danken Herrn Jean Christophe Thomas und der Revue d'histoire des facultés de droit et de la science juridique für die freundliche Genehmigung, diesen Artikel in deutscher Übersetzung zu publizieren.

Nous remercions M. Jean Christophe Thomas et la Revue d'histoire des facultés de droit et de la science juridique de nous avoir accordé l'autorisation de traduire ce texte pour le présent numéro.

Im Originaltext sind eine ganze Reihe von Quellenangaben fehlerhaft. Die Redaktion dankt dem Übersetzer, Nikolaus Gramm, für die Korrektur dieser Angaben, sowie Hélène Ménard (Université Paul Valéry - Montpellier und Jean-Michel David (Université Paris I Panthéon-Sorbonne) für weitere wertvolle Hilfe, insbesondere bei der Korrektur der Anmerkungen 11 und 34.

\section{I.}

1 Die von den Juristen des Römischen Reichs in ihren didaktischen Werken verbreitete Darstellung der Natur ist hinlänglich bekannt. Der erste Abschnitt (oder »Titel«) des ersten Buchs der Digesten stellt hierzu bedeutsame Fragmente zusammen, mit deren Hilfe sich zwei komplementäre, ohne allzu große Schwierigkeiten miteinander zu 
vereinbarende Doktrinen nachzeichnen lassen. Ulpians Institutiones betrachten das Naturrecht in seiner weitesten Ausdehnung. Dieses Recht ist für die Gesamtheit der Lebewesen gültig und vereint die Menschen mit den Tieren der Erde, des Meeres und des Himmels unter ein und derselben Verpflichtung, sich zu reproduzieren. Diesem "gemeinen« Recht unterstehen alle Lebewesen, die zur Fortpflanzung und zur Aufzucht ihrer Nachkommenschaft aufgerufen sind. Die wilden Tiere können sich genauso wenig wie die anderen der »Umsicht dieses Rechts « entziehen, d. h. der Organisation einer auf den Fortbestand der Spezies ausgerichteten Sexualität. ${ }^{1}$

2 Ein kleinerer, in den vorigen eingeschriebener Kreis umfasst die im eigentlichen Sinne menschlichen Institutionen. Man muss aber, wie es scheint, zwischen zwei aufeinander folgenden Zuständen der Menschheit unterscheiden. Der erste gehört noch der Natur an: Die Menschen sind dort frei, gleich und nicht nach ihrem Status unterschieden; sie erfreuen sich noch in ungeteilter Gemeinschaft an den Gütern der Erde; und sie sind keiner Herrschaft unterworfen. Die Institutionen Marcians, Florentins und Ulpians oder die Epitome Hermogenians stellen konvergierende Indizien für ein solches System bereit. ${ }^{2}$ Es lässt sich, wenn man so sagen darf, ex negativo definieren: Es kennt die sukzessiven Bestimmungen nicht, denen zufolge eine ganze Reihe miteinander verketteter Unterscheidungen - angesichts der Konkurrenz der Stadtgemeinden - die Statusunterschiede, Eigentumsansprüche und Handelsaktivitäten aufkommen lässt. Eine Negation der Unterscheidungen und der Grenzen, die das persönliche Geltendmachen des ius auf die Verteidigung des eigenen Körpers beschränkt. ${ }^{3}$ In einem späteren Zustand erscheinen endlich die Unterscheidungen und Grenzen, die seither ein überall befolgtes Rechtsregime konstituieren. Die Rechtsgelehrten der antoninischen und severischen Ära nennen es das ius gentium. Dieses universelle menschliche Recht, das zeitlich nach der Natur (aber nicht im Sinne der Natur) eingeführt wurde, umfasst Institutionen, deren Katalog definitiv auf das dritte Jahrhundert bezogen ist: Kriege (deren Resultate die Sklaverei und später die Freilassung der Sklaven sind), Völker, Königreiche, private Landgüter, Grenzen der Ländereien, Gebäude, Handel, einvernehmliche Verträge, Schuldverschreibungen. ${ }^{4}$ Es muss festgehalten werden, dass sie im Bruch mit dem Naturrecht definiert werden: nach diesem und sogar gegen es.

3 Gaius gründet das Völkergemeinrecht allerdings auf die naturalis ratio, und es ist üblich, bestimmte Institutionen des ius gentium mit der natürlichen Vernunft in Zusammenhang zu bringen. ${ }^{5}$ Dennoch bleibt die Grenze zwischen der natürlichen Vernunft des Menschen und den Normen des ius naturale, die auf eine ungeteilte menschliche Natur aufbauen, unüberwindlich. Die Juristen denken diese beiden Rechtsformen als zwei aufeinanderfolgende, aber einander widersprechende Gattungen: Zwischen Sklaverei und Freiheit, Status und Gleichheit, Eigentum und gemeinsamer Nutzung tut sich die ganze Distanz auf, die die Geschichte von dem trennt, was noch nicht Geschichte ist.

4 Für die Juristen der Kaiserzeit markiert der Krieg sicherlich die erste produktive Spaltung des Rechts. Im selben Zuge entstehen die Stadtgemeinden: Das ius civile zeichnet sich nicht als eine dritte Etappe der Rechtsentwicklung aus. Es ist lediglich die interne Projektion eines universellen Rechts, zu dem in jeder Stadtgemeinde gewisse Regeln hinzutreten oder von ihm wegfallen. ${ }^{6}$ Nach der meistverbreiteten Darstellung ist jedes Zivilrecht ein gesondert dargelegtes gemeines Recht. Dieses doppelte Schema ist relativ einfach. Auf der einen Seite besteht das Naturrecht, das allen Lebewesen 
gemein ist, mit dem Gesetz ihrer Reproduktion fort. Auf der anderen Seite ist das eigentlich menschliche Naturrecht praktisch verschwunden und hat einem ius gentium von gleicher Ausdehnung, aber antinomischer Natur Platz gemacht. Das Zivilrecht ist eine singuläre Version davon, die in die Grenzen der Stadtgemeinden eingeschrieben ist. Es ist nicht [natur-]gegeben, sondern gesetzt. Es entsteht zeitgleich mit den Staaten, deren Gründung es überwacht und in denen es zur Anwendung kommt.

Naturrecht, Völkergemeinrecht und Zivilrecht fügen sich so wie konzentrische Kreise auf ein und derselben Ebene zusammen. Die drei Bereiche sind nicht hierarchisch geordnet. Ihre Beziehung ist horizontal gedacht. Der äußerste Kreis umfasst die Lebewesen, der mittlere die Nationen und der kleinste die Stadtgemeinde. In jeder Stadtgemeinde universalisiert ein Netzwerk von Entsprechungen mit anderen internen Rechtssystemen das Feld seiner Normen, ohne dabei den Normen, die er mit anderen gemein hat, irgendeinen Vorrang über jene Normen einzuräumen, die ihm eigentümlich sind.

6 Die Juristen haben offensichtlich das Dispositiv umgestaltet, das ihnen die stoische und ciceronianische Tradition übermittelt hatte. Die Natur nahm dort eine prominente, inspirierende und legitimierende Stellung ein: ein mit der Natur im Widerspruch stehendes Recht hatte keine Rechtskraft. ${ }^{7}$ Dieses Modell war ihnen sicherlich über die Moralphilosophie und die politische Philosophie - und auch durch die Rhetorik, in der sie geschult waren - geläufig. Aber sie entnahmen daraus nur fragmentarische Aussagen und vereinzelte Formulierungen. So findet sich Ciceros berühmte Sequenz vera lex recta ratio, naturae congruens, diffusa in omnes, constans, sempiterna (»Es ist aber das wahre Gesetz die richtige Vernunft, die mit der Natur in Einklang steht, sich in alle ergießt, in sich konsequent, ewig ist [...]«; Cicero [1999], S. 205) ${ }^{8}$ in isolierte, verstreute, ihrer organischen Kohärenz beraubte Themen aufgespalten wieder. Gewisse Texte greifen das Thema der Fortdauer auf (constans et perpetua voluntas, Ulpian, Dig. 1.1.10 [»der unwandelbare und dauerhafte Wille«; Behrends [1995], S. 94]; id quod semper aequum ac bonum est, Paul, Dig. 1.1.11 pr. [»was allezeit gerecht und gut ist«; Behrends [1995], S. 94]; [...] divina quadam providentia constituta semper firma atque immutabilia permanent, Justinian, Inst. 1.2.11 [»[...] sind von wahrhaft göttlicher Vorsehung geschaffen worden und bleiben immer gültig und unwandelbar«; Behrends [1997], S. 5); andere erwähnen die Universalität der Natur (natura omnia animalia docuit, Ulpian, Dig. 1.1.1.3 [»was die Natur alle Lebewesen gelehrt hat«; Behrends [1995], S. 92]), die menschliche Universalität des ius gentium (quod vero naturalis ratio inter omnes homines constituit id apud omnes populos peraeque custoditur, Justinian, Inst. 1.2.1 [»Was dagegen die natürliche Vernunft für alle Menschen bestimmt hat, das wird bei allen Völkern gleichermaßen beachtet [...]; Behrends [1997], S. 3]; quae apud omnes gentes peraeque servantur, Justinian, Inst. 1.2.11 [»die bei allen Völkerschaften gleichermaßen befolgt werden«; Behrends [1995], S. 5]) oder die Wahrheit der Natur (naturae veritas, Papinian, Dig. 28.2.23; Ulpian, Dig. 50.1.6 pr.).

7 Fortdauer, Universalität, Wahrheit - dennoch greifen die Juristen die Idee nicht auf, dass das Recht seine Quelle in der Natur finden könnte. In den Digesten würde man eine Formulierung, die dem ciceronianischen ius a natura gleichkäme, vergeblich suchen. ${ }^{9}$ Ebenso wenig wird der normative Vorrang der Natur vor dem Recht zugestanden. Man ist weit davon entfernt, dass eine der Natur zuwiderlaufende Institution als illegitim erachtet würde oder dass das positive Recht sich einer naturae norma ${ }^{10}$ anpassen müsste. Die Sklaverei, deren Legitimität niemand in Frage stellte, war, 
wie man dachte, contra naturam ${ }^{11}$ entstanden, und das Gesetz (dem die kaiserlichen Constitutiones sich im Laufe des zweiten Jahrhunderts angeglichen hatten) kannte keine Grenze: Im öffentlichen Recht der Kaiserzeit war der Gesetzgeber, wie im Recht der republikanischen Zeit, nur an jene positiven Gesetze gehalten, an die er sich selbst gebunden hatte. ${ }^{12}$ Wenn die Natur in den juristischen Texten ein Hindernis darstellt, so ist es stets ein physisches Hindernis. So erlaubt sie es nicht, dass mehrere Kinder im selben Augenblick den Bauch ihrer Mutter verlassen, so dass auch bei Zwillingen und Drillingen die Reihenfolge der Geburt zwischen älteren und jüngeren Geschwistern unterscheidet. ${ }^{13}$ Sie fordert auch, dass ein Vater ein gewisses Alter hat, um seinen Sohn zu zeugen, so dass die Adoption, die "die Natur imitiert", einen Altersabstand von 18 Jahren zwischen Adoptierendem und Adoptiertem verlangt. ${ }^{14}$ Die Dauer unseres Lebens verbietet es, unsere Nachkommenschaft sich über mehr als drei Generationen erstrecken zu sehen: Daher gibt es logischerweise niemanden, der - zu Lebzeiten eines gemeinsamen Vorfahren - seine entfernteren Verwandten über den siebten Grad hinaus kennen könnte; daher beschränkt sich auch die Nomenklatur der Verwandtschaftsbeziehungen auf diese sieben Grade. ${ }^{15}$ Die Institutionen respektieren also gewisse Gesetze der biologischen Natur (wir werden später sehen, mithilfe welcher Fiktionen sie sich über diese hinwegsetzen). Dennoch sehen sie sich nicht durch eine moralische oder politische Natur begrenzt. Wenn die Juristen Hinderungsgründe ethischer Art unterstellen, beziehen sie diese auf die Gesetzmäßigkeit. So gibt es nach Paul [Julius Paulus] drei Gründe für das Unvermögen, Richter zu sein: lege, wenn jemand aus dem Senat verbannt wurde (d.h. in bestimmten Fällen des Ehrverlustes); moribus, für die Frauen und Sklaven; und natura, die Natur schließt Taube und Stumme aus. ${ }^{16}$ Oder auch noch jene Passage aus dem Kommentar zu den libri iuris civilis des Sabinus, wo zwei Gründe, ein Versprechen als nichtig anzusehen, sich gegenüberstehen: Sei es, weil die vereinbarte Gegenleistung dem Willen des Schuldners nicht unterworfen ist, da dieser sich verpflichtet hat, etwas zu tun "was die Natur nicht zulässt«; oder sei es, weil das Versprechen auf etwas Verbotenes abzielt: »Wenn man beispielsweise jemanden zu dem Versprechen verleitet, seine Schwester zu heiraten«: Im Gegensatz zu dem, was die Natur verbietet, rangiert der Inzest in dem Bereich, »den die Gesetze verbieten . $^{17}$

Man sieht im klassischen römischen Recht keine moralischen Tabus, die sich auf das Naturrecht gründen. Kein Jurist wäre etwa darauf verfallen, aus dem Inzest ein Verbrechen wider die Natur zu machen. Wenn die Natur in diesem Zusammenhang erwähnt wird, so geschieht das in einer ganz präzisen Hinsicht: Ein Freigelassener vereinigt sich mit seiner Mutter oder Schwester, die Sklavinnen sind, ein freier Mann heiratet die junge Frau, die er außerhalb der Ehe gezeugt hat. In diesen hypothetischen Fällen wird keine legitime Verwandtschaftsbeziehung anerkannt. Um das Verbot aufrechtzuerhalten, muss man dann an eine natürliche Verwandtschaftsbeziehung appellieren; die Natur weitet die Heiratsverbote nicht unmittelbar über ihren eigentlichen Bereich aus: Sie setzt ein substitutives Verwandtschaftsverhältnis ein, um den juristischen Verboten ein Substrat zu verschaffen. ${ }^{18}$ Das Verbot wird, in letzter Instanz, durch das Gesetz und die mores begründet: ${ }^{19}$ Man geht keineswegs über eine staatsbürgerliche und ganz und gar soziale Legalität hinaus. Dasselbe gilt für die Überschreitungen der pietas gegenüber Vater und Mutter. Die aus der Pietät abgeleiteten Pflichten wurden von den Rhetoren der Republik unter der Rubrik natura verbucht. Für den Juristen Pomponius gehören sie nur noch zum ius gentium. ${ }^{20}$ Die Natur wird hier jedoch noch eingeführt, um zwischen Kindern und Eltern in Sklaverei, 
oder zwischen illegitimen Kindern und unverheirateten Eltern ein Band zu behaupten, das die Anwendung jener Pietätsregeln sicherstellt, die den legitimen Nachfahren auferlegt sind. Bereits im augusteischen Zeitalter untersagte der Rechtsgelehrte Labeo, gegenüber einer Mutter, die jemanden als Sklaven oder Bastard geboren hatte, vor Gericht Ansprüche geltend zu machen..$^{21}$ In der severischen Epoche autorisierte eben dieses natürliche Band, einen Sohn strafrechtlich zu belangen, der seine Mutter schlecht behandelte oder pietätlos Hand an sie legte. In einem Text Ulpians sieht man den Präfekten einer Stadt den Respekt dieser pietas erzwingen: Unter den Bürgern wird diese als publica definiert; unter Mitfreigelassenen gilt sie secundum naturam..$^{22}$ Ebenso kann ein Sklave des Verwandtenmordes beschuldigt werden, obwohl er rechtlich gesehen weder parentes noch cognati hat. Denn wie Veneleius Saturninus schreibt, selbst wenn die Sklaven nicht vom Buchstaben des Gesetzes betroffen sind, findet das Recht auf sie Anwendung, »da die Natur ihnen gemeinsam ist« - da die Natur den Sklaven die Verwandten gibt, die das Recht ihnen verwehrt. ${ }^{23}$

Ohne im mindesten Normen zu begründen, bereitet die Natur laut den Juristen des zweiten und dritten Jahrhunderts bloß das Terrain dafür, die Normen über den Bereich der Gesetze hinaus auszuweiten. Ohne dabei zu helfen, die Verbote zu denken, wird sie $\mathrm{zu}$ deren Ausweitung in Dienst genommen. Wenn man hingegen berücksichtigt, dass das Recht Justinians die Verbrechen "wider die Natur « ${ }^{24}$ stigmatisiert, und dass die Kirchenväter im Allgemeinen - gemäß der paulinischen Formel des universellen Moralgesetzes $^{25}$ - eine Äquivalenz zwischen dem offenbarten göttlichen Gesetz und dem natürlichen, in die Herzen der Menschen eingeschriebenen Recht postulieren, wird es unumgänglich, dieser originellen Struktur der römischen Rechtsethik Aufmerksamkeit zu schenken. Es gibt, dieser Ethik zufolge, keine andere Quelle des Rechts als die Gesetze und die mores der Stadtgemeinde.

Die Einführung des Naturrechts in die juristische Problematik des Kaiserreichs setzt die Vision eines universellen Rechts voraus, aber sicherlich nicht die eines Rechts, das die Grundlagen des Rechts vorschreibt. Die Natur wird nicht als Abbild einer letzten und grundlegenden Norm benutzt. Sie fungiert nicht als ein Prinzip, das sich dem menschlichen Gesetzgeber aufzwingt. Es wird, im Gegensatz zum ciceronianischen Modell, keine Hierarchie von Natur- und Zivilrecht nahegelegt.

11 Die Rechtswissenschaft nimmt so Motive in sich auf, deren Sinn radikal verändert wurde. Man schenkt dieser Arbeit, bei der die Juristen mit Hilfe anderweitig entlehnter Texte ein autonomes Denken produzieren und dabei ihrem Gesetzeswerk philosophische Gemeinplätze einfügen, nicht genügend Aufmerksamkeit. Die juristische Behandlung des Naturrechts zeigt, dass die Transzendenz nicht die Dimension ist, in die die Juristen Roms ihre Normen eingeschrieben haben. Dennoch ist die "Natur" einer dieser monumentalen Begriffe, die der üblichen Ansicht nach ein metaphysisches Engagement voraussetzen: Es wäre beinahe ungehörig, den Juristen, die sich auf sie berufen, keine gedankliche Höhe zuzuschreiben. Vergegenwärtigen wir uns einmal die Institutiones Ulpians, die die Digesten eröffnen. Der Vorhang hebt sich, und wir werden Zeugen des Kultes, die der von der Kontemplation des Wahren - er strebt "wahrhaft nach Philosophie, nicht nur dem Anschein nach ${ }^{26}$ - erschöpfte Priester-Rechtsgelehrte der Gerechtigkeit darbringt. Dieses Anfangsbild muss in Szene gesetzt werden, um den ganzen Apparat der großen Begriffe aufzubieten: das öffentliche Recht und das Privatrecht, dann die Natur und ihre Menschheit des 
Goldenen Zeitalters; die gegeneinander aufgehetzten Völker, die Kriege, die Kriegsgefangenschaften und das Zersplittern dieser Einheit in Königreiche, Stadtgemeinden und Gebiete, und die Wiederherstellung dieser Einheit durch den Handel und die Verträge, durch die die Bürger all dieser Stadtgemeinden sich untereinander verbinden; jede Stadtgemeinde ist so schließlich eine kleine Bühne der ganzen Welt.

In diesem riesigen Theater werden die Kategorien installiert. Doch der Jurist hat die vermeintliche Ordnung der Dinge hinter dieser trompe-l'œil-Fassade schon umgestürzt. Denn die Natur ist abgesetzt; sicherlich in einem unzugänglichen Vorher isoliert, aber vor allem klug auf die Sphäre des Privatrechts eingeschränkt. Nach dem Plan der Institutiones wird die Dreiteilung Natur - gentes - Stadtgemeinde nach der summa divisio des ius in öffentliches und privates Recht eingeführt. ${ }^{27}$ Der Staat und die Privatpersonen sind schon definiert, wenn die Natur die Bühne betritt. Wenn die Juristen aber das Naturrecht in seinem eng umgrenzten Bereich feiern, beschwören sie diese universelle Natur und diese Menschheit ohne Status und Grenzen herauf. Der Widerspruch zwischen der dieser Natur eigenen Universalität und der Enge des Raums, den ihr die Topik des Rechts zugesteht, ist unübersehbar. Muss man also annehmen, dass irgendeine Enklave davon in der internen juristischen Ordnung erhalten ist? Mehr noch als eine Utopie oder ein in den Randbemerkungen ihrer Werke angerufenes Goldenes Zeitalter führen die Juristen vorweg die Fiktion ein, dass das Recht sich in die Natur einschreibt. Weit davon entfernt, einer schmückenden Lehre Nahrung zu geben, wird das Naturrecht unter die Gliederungen des Privatrechts eingereiht. Wir gehen jede Wette ein, dass sein Gebrauch strikt kontrolliert werden wird. In der Tat müssen wir jetzt die allzu allgemeinen Sätze der didaktischen Abhandlungen hinter uns lassen, aus denen wir nichts mehr lernen können. Es gibt viel mehr in den juristischen Kombinationen $\mathrm{zu}$ entdecken, in deren Dienst die Natur in der Kasuistik mobilisiert wird.

II.

13 Im Zeitalter der Natur war alles allen gemeinsam. Beginnen wir mit dieser Figur der ursprünglichen Gütergemeinschaft, die dazu dient, gewisse Formen der Aneignung zu denken und zu begründen. Denn jenseits der häufig auf die Dinge angewandten Unterteilungen - zum vererbten Besitz gehörig oder nicht, von göttlichem oder menschlichem Recht, öffentlich oder privat - erkennt man eine Kategorie von Gütern, »die zuerst von der Natur hervorgebracht wurden, und die noch nicht in persönliches Eigentum übergegangen sind «. ${ }^{28}$ Diese ursprünglichen Güter bestehen in einem begrenzten, durch die Juristen definierten Bereich fort. Die einen sind »nach Naturrecht allen gemeinsam« oder auch noch in »öffentlicher Benutzung [gemäß] dem Völkergemeinrecht «. ${ }^{29}$ Dies trifft auf die Luft, das Meer und seine (durch die höchste Flut des Winters bestimmten) Strände zu. Innerhalb dieser Grenzen ist die Natur im Prinzip dem Recht der Privatpersonen entzogen, ohne dass sie deswegen den Stadtgemeinden gehörte, die ihre Nutzung kontrollieren, aber nicht verbieten oder für sich selbst reservieren können. Andererseits bringt die Natur auch Güter hervor, die für die private Besitznahme bestimmt sind: die wilden Tiere die, einmal eingefangen, dem Subjekt gehören, das sie domestiziert. ${ }^{30}$ 

Regime auf. Dem ungeteilten Nutzungsrecht der gemeinsamen Dinge steht das exklusive Recht gegenüber, das die erste Inbesitznahme verleiht. Diese beiden Regime stehen im Kontrast zueinander und sind dennoch fest miteinander verbunden, insofern sie beide in der Enklave eingeschlossen sind, in der das Recht eine autonome Natur fortbestehen lässt. In diesem prä-juristischen Gehege koexistieren - gleichsam als Fossilien - die beiden Formen des Kollektiven und des Privaten, die das Eigentum in der zivilen Welt annimmt. Kurz gesagt: Die Natur präfiguriert die Institutionen und wird zugleich von ihnen definiert.

Die res communes, Meer und Strände, bilden außerhalb einer jeden Stadtgemeinde ein Modell für diese Dinge, die in den Stadtgemeinden als öffentlich bezeichnet und gemeinschaftlich genutzt werden: Flüsse, Straßen, Plätze, Theater, Märkte, Bäder usf. Denn die Juristen verstehen diese Güter nicht als Eigentum des Staates, sondern vielmehr als gemeinsamen Besitz der cives: eine kollektive Aneignung, die ihnen bisweilen die Benennung res universitatis einbringt. ${ }^{31}$ Die res communes und die res publicae sind freilich nicht dasselbe; die Auflistungen der einen und der anderen kommen nicht miteinander zur Deckung. Aber ihre Verknüpfung drängt sich auf, so als ob das gemeinsame Nutzungsrecht der Natur das Miteigentum unter Staatsbürgern vorwegnähme. ${ }^{32} \mathrm{Ihr}$ vom Privatbesitz ausgenommener Status (extrapatrimonialité), dessen Quellen in der Natur liegen, reproduziert sich nach einem Text Pauls im ius gentium und in den Gebräuchen der Stadtgemeinden. ${ }^{33}$ Es braucht daher nicht zu verwundern, dass die Juristen der Kaiserzeit die Meeresstrände unterschiedslos als gemeinschaftlich und als öffentlich definierten. Und auch nicht, dass sie diese Begriffe kombinierten, indem sie einen "gemeinschaftlichen Gebrauch der öffentlichen Dinge« und einen »öffentlichen Gebrauch der gemeinschaftlichen Dinge « postulierten. ${ }^{34}$ Diese Schwankungen sind wahrscheinlich nicht Zeichen einer doktrinalen Unschlüssigkeit oder einer historischen Entwicklung. Das Miteigentum der res publicae war ganz einfach als die den Stadtgemeinden eigentümliche Form eines Gemeineigentums konzipiert, das zunächst eine Norm der Natur gewesen war, bevor es das Recht in enge Grenzen zwängte.

16 Analogie ohne Verwirrung: Denn in der Stadtgemeinde war die öffentliche Natur der Plätze eine fortdauernde Institution. Die richterlichen Verbote erlaubten es jedem Bürger, sich ihrem privaten Gebrauch durch wen auch immer zu widersetzen. Der Schutz des Rechts aller Bürger war der Wachsamkeit eines jeden einzelnen anvertraut. ${ }^{35}$ Dagegen unterstanden die nach der Natur gemeinsamen Dinge dem provisorischen dominium des Besitznehmers. Wer etwa auf Pfählen baute und eine Insel im Meer errichtete, der schnitt sich für eine gewisse Zeit einen Teil dieser Natur heraus, die noch niemandem gehörte und daher jedem zustand..$^{36}$ Für eine gewisse Zeit nur, denn die Natur kennt keine Verjährung: ${ }^{37}$ man wird bei sich bietender Gelegenheit erleben, wie sie wieder in ihre Rechte eintritt. Wenn das auf dem Ufer errichtete Gebäude zerstört wird, gewinnt der besetzte Boden seinen ursprünglichen Zustand zurück: Er kehrt in pristinam causam zurück. ${ }^{38}$ Marcian vergleicht dieses Recht der Natur, das ein menschliches Recht für einen Augenblick suspendiert hatte, mit der Lage eines Kriegsgefangenen, der seine ursprüngliche Freiheit wiederfindet, sobald er die Grenze [zu seinem Heimatland; A.d.Ü.] überschritten hat: quasi iure postliminii revertitur locus in pristinam causam (»das Grundstück [kehrt] gleichsam nach dem Rückkehrrecht in seine ursprüngliche Rechtslage zurück«, Behrends [1995], S. 139). ${ }^{39}$ 
17 Das Nutzungsrecht der res communes unterscheidet sich schließlich von dem des patrimonium populi, das sich aber dennoch an ihm orientiert, insofern die ursprünglichen Güter noch nicht dem dominium von wem auch immer unterstehen und somit wenigstens für eine gewisse Zeit in Besitz genommen werden können. ${ }^{40}$ Ihre Qualität, res nullius zu sein, ist ausschlaggebend: Sie ist nicht die Folge einer Handlung, die sie entweder den Göttern der Stadtgemeinde oder deren Bürgern unterstellt. ${ }^{41}$ Von Natur aus gehören sie niemandem und zugleich allen, was sie zu einer Form abwechselnd öffentlicher und privater Aneignung prädestiniert: Was ein Privatmann dem Meer abringt, schreibt Ariston im ersten Jahrhundert, wird vom Meer zurückgeholt, das das öffentlich macht, was es wieder in Besitz nimmt; ${ }^{42}$ und ebenso wird der Teil der Küste, auf dem die Spuren der Besitznahme verschwinden, wieder in die natürliche ungeteilte Rechtsgemeinschaft zurückfallen. Die Wiederherstellung dieser gemeinschaftlichen Natur löscht nicht jedes Recht, sondern allein das der Privatleute aus.

18 Angesichts dieser res communes entwerfen die Juristen ein ganz anderes rechtliches Regime der Natur. Es betrifft die ursprünglich autonomen res nullius: Das sind die wilden Tiere, die vom Recht in dem Augenblick erfasst werden, an dem sie zum ersten Mal eingefangen werden. ${ }^{43}$ Der Jäger ergreift keineswegs seinen Teil der gemeinschaftlichen Reichtümer, sondern er verwandelt das, was ursprünglich sich selbst gehört, in ein Objekt seines Eigentums. Er übt nicht ein Recht aus, das ihm seine Teilhabe an einer Gemeinschaft des Nutzungsrechts virtuell schon erteilt hätte. Indem er aus dem jedem Recht entzogenen Tier eine ihm gehörende Sache macht, verwirklicht er die erste Aneignung des Privatrechts: eine Handlung, durch die er sich einseitig, ohne jede soziale Bevollmächtigung, als Rechtssubjekt einsetzt. ${ }^{44}$

19 Nach der klassischen Theorie der Erwerbstitel ist jedes Gut immer schon in die Kreisläufe von Weitergabe und Tausch eingebunden: Ein Besitz stützt sich auf notwendigerweise sekundäre Gründe. Dies sind die Titel, die sich aus der Eigenschaft, Erbe zu sein und aus Übertragungen gegen Entgelt oder unentgeltlicher Art ergeben. ${ }^{45}$ Die allererste Besitzergreifung hinterlässt in der Erfahrung oder gar im Denken keine Spur. Als eine Ausnahme davon lässt aber das Einfangen eines Tieres eine Spur, ein vestigium, zurück, von dem aus kluge Menschen in der Zeit zurückgehen, um diese ursprüngliche Besitzergreifung zu erfassen:

20 »Nerva der Jüngere (1. Jh. n. Chr.) sagt, dass das Eigentum an den Sachen mit der natürlichen Besitzergreifung begann, von der eine Spur im Einfangen der Tiere von Himmel und Erde erhalten ist. Denn uns gehören typischerweise die Dinge, die wir als erste an uns gerissen haben, um sie zu besitzen.« (Dig. 41.2.1.1.; übers. nach Thomas; N.G.). ${ }^{46}$

21 Als letzte Zeugen der Handlung, durch die das erste Subjekt seinen Besitz an sich gerissen hat, scheinen die Tiere des Himmels, der Erde und des Wassers nur noch in Erwartung ihres »Besitznehmers« (occupans, capiens) zu fliegen, zu laufen und schwimmen. Exakt bei dieser Gelegenheit definieren die Rechtsgelehrten eine Form des Erwerbs, aus der sich erschließen lässt, was die "natürliche Besitzergreifung" am Anfang gewesen sein musste. Das Einfangen der wilden Tiere (und die des Menschen im Krieg) wird wie ein letztes Relikt behandelt, mit dessen Hilfe das Recht eine rechtlich unmögliche, doch für das Denken des Rechts notwendige Handlung denken kann.

Von den Netzen einer gelehrten Kasuistik erfasst, bieten sich die wilden Spezies dem Experten vorteilhaft an, der mit scharfem Auge den kostbaren Moment der ersten 
Handlung isoliert: capere, ergreifen. Die Bestimmung dieses Moments ist schwieriger als es scheint. Darf man sagen, dass das Tier schon durch den ersten Blick des Jägers zum Eigentum wird, der es in sein Blickfeld einschließt? ${ }^{47}$ Oder muss man abwarten, bis das Tier verwundet ist? Was gilt aber, wenn das verletzte Tier die Flucht ergreift? Manche, wie Trebatius Testa (ein Zeitgenosse Cäsars) waren der Ansicht, dass das Tier dem ersten »Besitznehmer" gehörte, sofern er seinen Schuss durch eine anhaltende Verfolgung bekräftigte, und dass er somit einen Dritten, der dieses Tier in betrügerischer Absicht in seine Gewalt gebracht hatte, wegen Diebstahls belangen könnte; wenn das verletzte Tier aber nicht weiter verfolgt würde, würde es seine natürliche Freiheit wiedererlangen, wieder in das rechtliche Regime der Natur zurückkehren und - wie in seinem ursprünglichen Zustand - eventuell in das Eigentum eines neuen »Besitznehmers « übergehen.$^{48}$ Orthodoxer war die Ansicht jener, die ein wirkliches Einfangen für notwendig erachteten. Man musste den Körper des Tieres gepackt, ihn in der Hand gehabt haben, um einen Rechtstitel zu erlangen. Welchen Titel aber? Den, den die Juristen ganz spezifisch als pro suo benannten: als das »Seinige«.

Hier muss kurz an ein technisches Detail des Rechts erinnert werden. Die Theorie der Eigentumstitel wird unter dem Aspekt der Verjährung der Besitzergreifung dargestellt, die die gesamte römische Theorie der possessio beherrscht. Als Hypothese stelle man sich vor, dass ein Käufer seine Habe in gutem Glauben von einem Dritten erworben hat, der aber nicht dessen Eigentümer war (a non domino), oder dass der Akt des Verkaufs in formaler Hinsicht fehlerhaft war. Die Ersitzung hat dann aber die rechtliche Fehlerhaftigkeit getilgt und eine juristisch unangreifbare Position geschaffen, da die gesetzliche Verjährungsfrist die Fehlerhaftigkeit schließlich behoben hat. Um sein Eigentum zu bestätigen, muss der Käufer sich allerdings auf einen der Titel, die in Kapitel 4 bis 10 des 41. Buchs der Digesten dargestellt werden, berufen können. Wenn er in einem Prozess beschuldigt wird, [das Eigentum unrechtmäßig erworben zu haben; A.d.Ü.] antwortet der bona-fide-Eigentümer, dass er die Sache pro emptore, als Käufer, erworben hat, - pro herede, als Erbe (sei es, dass er glaubte, der Erbe zu sein, sei es, dass er annahm, dass diese Sachen zu seinem Erbe gehörten), - pro donato, pro legato, pro dote, weil er als Geschenk, als Vermächtnis oder als Mitgift das erhalten hat, was dem darüber Verfügenden gar nicht gehörte - oder pro derelicto, wenn er etwas an sich genommen hatte, das (wie er glaubte) von seinem Inhaber verlassen worden war. Am Rande sei bemerkt, dass der occupans hier nicht in dieselbe rechtliche Kategorie gehört wie der Jäger eines Tiers. Die Aufgabe eines Besitzes durch seinen Inhaber stellt [dem, der sich dieses Gut aneignet; A.d.Ü.] einen Besitztitel bereit. In gewisser Weise hat der Dritte diese Sache durch eine Übertragung erhalten, deren beide Momente, der Verzicht und das In-Besitz-Nehmen, sich als eine sicherlich diskontinuierliche, aber eine Einheit bildende Operation verketten und analysieren lassen.

Alle diese abgeleiteten Gründe des Eigentums setzen voraus, dass die Sache, die der Eigentümer besitzt oder zu besitzen glaubt - in welcher Form auch immer - von einem anderen auf den neuen Eigentümer übertragen wurde. Das Subjekt besitzt, was es von einem anderen erhalten hat. Die durch das Recht für die Beziehungen der Subjekte untereinander festgeschriebenen Rollen müssen übernommen werden. Diese Regel lässt den singulären Charakter des [Eigentums-]Titels pro suo umso deutlicher werden. Der Besitzer, der das Seinige für sich in Anspruch nimmt, macht keine Beziehung zu irgendeinem anderen geltend. Er nimmt nur seine ursprüngliche Beziehung zu dieser Sache in Anspruch. Er antwortet im Verlauf des Prozesses nicht, er habe sie gekauft, 
geerbt, als Geschenk, Vermächtnis oder Mitgift erhalten oder aber als verlassen erachtet, sondern nur, dass er sie für die seinige halte: ohne jede andere Grundlage, als jene, die das reflexive Possessivpronomen zum Ausdruck bringt, und ohne einen Besitztitel nachweisen zu können, der seinem Besitz der Sache vorausginge. Doch es ist nun so, dass sich die Natur direkt seinem Zugriff angeboten hat oder dass sie sich spontan in seine Besitztümer eingegliedert hat. Denn in den Texten zur Rechtsprechung deckt der Titel pro suo ausschließlich das Einfangen wilder Tiere und die Hinzufügung von Schwemmland [zum eigenen Besitz; A.d.Ü.] ab. ${ }^{49}$ Die zivilrechtliche Interpretation schließt sich hier dem natürlichen Wachstum der von der Tradition übermittelten Sache an; so zum Beispiel die Leibesfrucht der schwanger gekauften Sklavin: Die Mutter war ein Besitz pro emptore, das neugeborene Kind, Gabe der Natur, ein Besitz pro suo, allein mit dem Titel des Seinigen.

Der Titel pro suo erscheint als solcher, wenn der Erwerb ein originaler ist, kein abgeleiteter: als solcher, in dem Maße, wie er auf eine eindeutige juristische Qualifikation antwortet. Denn einer späteren Theorie zufolge, in der der Titel nicht mehr spezifisch definiert wird, rechtfertigt sich jeglicher Besitz letzten Endes durch eine doppelte Überlegung: die einer besonderen Übertragung, die uns denken lässt, dass wir die Sache eines Anderen in Händen halten, und die der Zugehörigkeit im Allgemeinen, die uns denken lässt, die Sache sei die unsrige. ${ }^{50}$ Das reflexive Possessivpronomen suus vereint infolgedessen alle singulären Titel in einem einzigen Ausdruck. Allerdings handelt es sich um eine didaktische Kategorie: Es ist keine Qualifikation, die man vor Gericht gelten machen könnte. Im römischen Recht gelten nur die Gründe, die man namhaft macht. Sich auf das "Seinige« zu stützen, läuft notwendigerweise - worauf Paul hinweist - darauf hinaus, sich auf eine species possessionis zu berufen: auf jene nämlich, die durch Besitznahme oder durch Anschwemmungen erreicht wird. ${ }^{51}$

Wenn wir uns wörtlich an die Qualifikationen des römischen Rechts halten, wird als im eigentlichen Sinne "seinig« nur die allererste Nutzung einer Natur betrachtet, die es auf dieser Welt praktisch nicht mehr gibt. Wenn die Juristen in ihren kasuistischen Kombinationen diese wilde Natur inszenieren, die nur für eine ausschließlich das "Seinige« für sich in Anspruch nehmende Aneignung anfällig ist, so geschieht dies, um eine Freiheit $\mathrm{zu}$ formulieren, durch die - solange sie nicht domestiziert ist - die Ausübung des menschlichen Rechts vereitelt wird. So also in einem Sammelband für die Schule unter dem Titel »Alltagsdinge« oder »Gästebuch« die Fabel der Bienen, deren

"Natur wild (fera) ist. So werden jene, die sich in einem Baum in unserem Besitz als Schwarm niederlassen und noch nicht von uns in einen Bienenstock eingeschlossen werden, nicht stärker als unser Eigentum angesehen als die Vögel, die in dem Baum nisten, der uns gehört ... Die Honigwaben, die sie produzieren, kann irgendjemand an sich nehmen, ohne dass dies Diebstahl wäre ... Der Schwarm, der von unserem Bienenstock davonfliegt, bleibt dieser Ansicht nach der unsrige, solange wir ihn nicht aus den Augen verlieren und solange es nicht allzu schwierig wird, ihn wieder einzufangen; andernfalls gehört er dem Besitznehmer. « ${ }^{52}$

Oder auch die Pfauen und Tauben, die ebenso wie die Bienen davonfliegen und wieder zurückfliegen (avolare, revolare) und dabei unser Recht über sie von ihrer »Absicht« abhängig machen, in unsere Ländereien zurückzukehren (animus revertendi) - eine Intention, die sich in einer Gewohnheit zeigt, aus der sich ihr Wunsch, uns zu gehören, unzweifelhaft ablesen lässt. ${ }^{53}$ 
Der Kasuistik der Besitznahme geht so die relative Klarheit ihrer Konturen verloren. Denn das Ergreifen des verwundeten Tiers verwirrt sich mit dem Recht über das provisorisch gezähmte Tier. Ein und dieselbe Kategorie umfasst das, was man [mit Gewalt] ergreift, und das, was man [ohne Zwang] erhält; so als ob das Recht, um den originalen Titel pro suo zu denken, es hätte versuchen müssen, die beiden konträren Autonomien des Subjekts und der ihrerseits als Subjekt betrachteten Natur zu versöhnen, da das Tier sich in seinem ursprünglichen Status immer auf diesen zurückbesinnen und »unserer Hut entfliehen und seine natürliche Freiheit wiedererlangen $\aleph^{54}$ kann. Daher rührt diese juristische Darstellung einer Rache der Natur, die sich Pomponius (zweites Jahrhundert n. Chr.) nach den analytischen Regeln des Prozesses für einen fiktiven Fall ausmalte:

»Hier die Spezies, mit der Pomponius zu schaffen hat. Wölfe hatten meinem Hirten die Schweine entrissen, die er hütete. Ein Siedler aus einem nahegelegenen Hof verfolgte sie mit seinen kräftigen tapferen Hunden, mit denen er sonst seine Herde zur Weide trieb, und nahm den Wölfen die Schweine ab - oder vielmehr retteten die Hunde sie. Mein Hirte verlangte, dass man ihm seine Schweine zurückgebe. Die Frage, die sich nun stellte, war die, ob die Schweine das Eigentum dessen geworden seien, der sie den Wölfen weggenommen hatte, oder ob sie weiterhin mir gehörten: Denn sie waren bei einer Art von Jagd eingefangen worden. Er (Quintus Mucius Scaevola, ein Rechtsgelehrter des späten zweiten Jahrhunderts v. Chr., auf dessen Urteil Pomponius hier vermutlich anspielt) dachte jedoch, dass die wilden Tiere, die man auf der Erde oder im Meer einfängt, nicht mehr den Menschen gehören, die sie gefangen haben, sobald diese Tiere ihr natürliches Milieu wiedergefunden haben, und dass ebenso die Tiere in unserem Besitz, wenn sie von Meeres- oder Landtieren davongerissen werden, nicht mehr uns gehören, sobald diese Tiere unserer Verfolgung entkommen. Wenn folglich das Tier, dass aus den Klauen eines anderen wilden Tieres gerettet wurde, nicht mehr uns gehört, so wird es dem Besitznehmer genauso gehören wie der Fisch, das Wildschwein, der Vogel, die unserer Herrschaft entfliehen und dann von einem Fremden gefangen werden und ihm gehören. ${ }^{55}$

Man könnte weitere Beispiele anführen, den Fall eines wilden Tiers erwähnen, das zuerst in die Falle geht, die A aufgestellt hat, dann aber von B befreit wird, der seine Beute verliert: Trotz der Unterschlagung, die zum Nachteil des ersten Wilderers begangen wurde, macht sich der zweite nicht des Diebstahls schuldig, da die Freiheit, die das Tier wiedererlangt hat, das unlauter erworbene Recht des ersten Wilderers zunichtemacht. Aus dieser Kasuistik ergibt sich die Idee, dass der ursprüngliche Titel gemäß der Topik der Besitznahme - der einzige ist, der nicht garantiert werden kann. Die Natur führt Kehrtwenden herbei, annulliert Rechtslagen, die ihr ungünstig sind, unterbricht die Kontinuität des Besitzes, der laut der Rechtsordnung ohne Unterbrechung oder wenigstens ohne zwischenzeitliche Unklarheit fortbesteht oder vererbt wird, dessen einstweilige Bewirtschaftung aber nicht organisiert oder geregelt ist.

Angesichts des einzigen primären und originären Titels, dessen ganze rechtliche Qualifikation am reflexiven Possessivpronomen pro suo hängt, das den Besitzer als autonome Quelle seines Rechts zeigt, postulieren die lateinischen Rechtsgelehrten einen Einbruch des Zufalls in die Ordnung, ein Eindringen des Unstetigen in das Stetige. Als ob jener Besitz, demgegenüber das Subjekt offensichtlich und formal über die größte Autonomie verfügt, sich auch als der erweisen sollte, bei dem er am wenigsten Herr des Seinigen ist. 
30 Aber zugleich dient die - in der Natur eingesetzte - rechtliche Kategorie des »Seinigen « als Referenz, um die private Aneignung in dem zu denken, was an ihr irreduzibel ist. So spricht sich die Natur, trotz der utopischen Ansicht, die die Lehrwerke von ihr präsentieren, in der Kasuistik äußerst genau über die unentbehrlichen Gliederungen des Rechts aus. In ihr schreiben sich bereits die öffentlichen und privaten Formen des Eigentums ein. Sie vereint die Nutzungsgemeinschaft mit der autonomen Ausübung des subjektiven Rechts. Jenseits einer vagen Referenz an die Idee, wonach die Institutionen sich an eine sie transzendierende Ordnung anpassen müssen, bietet sie den Juristen, im Innern des Zivilrechts selbst, einen Spiegel, in dem sie das Doppel ihres Rechts darstellen können.

III.

31 Wenn man nun das Thema der natürlichen Freiheit betrachtet, gegen die sich die Sklaverei richtet, sieht man, dass diese angeborene Freiheit wiederum präzisen rechtlichen Mechanismen entspricht. Was die Juristen als Natur postulieren, folgt aus einer Analyse der Verfahren, die sie verwirklichen. Auf der einen Seite schreiben zahlreiche Texte die Institution der Sklaverei der menschlichen List zu. Florentin: »Die Sklaverei ist eine Einrichtung des Völkergemeinrechts, durch die jemand entgegen dem Naturzustand dem Eigentum eines anderen unterworfen wird.« (Dig. 1.5.4.1; Behrends [1995], S. 118); Ulpian: »Diese Einrichtung entstammt dem Völkergemeinrecht, da nach Naturrecht ja alle frei geboren wurden und, als man die Sklaverei noch nicht kannte, auch die Freilassung unbekannt war. Nachdem sich aber die Sklaverei durch das Völkergemeinrecht ausgebreitet hatte, folgte ihr die Rechtswohltat der Freilassung." (Dig. 1.1.4; Behrends [1995], S. 93); »Im Zivilrecht werden die Sklaven nicht als Personen angesehen (pro nullis habentur); dies ist aber im Naturrecht nicht der Fall, da nach diesem Recht alle Menschen gleich sind « (Dig. 50.17.32; nach Thomas übersetzt); Tryphonin: "So wie nämlich die Freiheit auf dem Naturrecht beruht und das Eigentumsrecht an Sklaven durch das Völkergemeinrecht eingeführt worden ist [...] « (Dig. 12.6.64; Behrends [1999], S. 131); Justinian: »Nach Naturrecht wurden nämlich am Anfang alle Menschen frei geboren« (Inst. 1.2.2; Behrends [1997], S. 3). Man kann hier auch eine Passage bei Paul hinzufügen: Es ist den Sklaven, ebenso wie den Frauen, nicht von der Natur (natura) verwehrt, Richter zu werden, sondern von den Gebräuchen (moribus): "[...] aufgrund des Herkommens [ist es] den Frauen und den Sklaven [untersagt], nicht weil es ihnen an Urteilsfähigkeit mangelt, sondern weil anerkannt ist, daß sie keine bürgerlichen Ämter bekleiden können.« Dig. 5.1.12.2; Behrends [1995], S. 472). Man sieht auch, dass in dem Augenblick, in dem das Recht die natürliche Freiheit abschafft, es diese partiell durch die Freilassung wiederherstellt; das beneficium manumissionis korrigiert die Spaltung, die die Sklaverei in die aufgegliederten Gesellschaften einführt: secutum est beneficium manumissionis (»[es] folgte ihr die Rechtswohltat der Freilassung « [Inst. 1.5., Behrends (1997), S. 8]), sagt Justinian [korr. N.G.]. Und ebenso wie das entfliehende Tier seine naturalis libertas wiedererlangt - oder wie die Küste, sobald das Gebäude zerstört ist, in pristinam causam (»in ihre ursprüngliche Rechtslage«; Dig. 6.1.59) zurückkehrt, wie der Kriegsgefangene, der in sein Heimatland zurückgekehrt ist - so wie "die durch die Kriegsgefangenschaft in Sklaverei geratenen freien Männer, sobald sie dem Machtbereich des Feindes 
entkommen sind, ihre ursprüngliche Freiheit wiedererlangen (recipiunt in pristinam libertatem)« (Gaius, Dig. 41.1.7 pr.; nach Thomas übersetzt).

Der befreite Kriegsgefangene kehrt in die Freiheit zurück, in die er hineingeboren ist. Die Freiheit des freigelassenen Sklaven ist dagegen nicht angeboren, und wird auch nicht als angeboren betrachtet. Es bestehen jedoch Prozeduren, die in einer radikaleren Weise die Sklaverei auslöschen und die Freigeborenheit oder deren Anschein verleihen. Der goldene Ring, den der Prinzeps bestimmten Freigelassenen verleiht, trägt schon zur Illusion einer freien Geburt bei, seit eine lex Visellia unter Tiberius, im Jahr $24 \mathrm{n}$. Chr., den durch das ius anuli aurei Begünstigten den Zugang zu öffentlichen Ehrentiteln gewährte. Der libertus schien von da an dem von Geburt an Freien gleich zu sein, ohne dies wirklich zu sein: nach einer Formulierung Papinians, die in die Constitutio Diokletians übernommen wurde, besaß er die imago ingenuitatis. ${ }^{56}$ Die Natur wurde imitiert, die Freigeborenheit simuliert. Aber man konnte noch weiter gehen. Der Kaiser gestand die Freigeborenheit - und nicht mehr nur ihr Bild - zu, wenn er den Freigelassenen durch eine außergewöhnliche Gunstbezeigung wieder in die »Rechte seiner Geburt « (restitutio in natalibus) einsetzte. Aus einem in der Sklaverei geborenen Menschen machte er ganz offiziell einen von Natur aus Freien. Der Mechanismus dieser Prozedur setzt voraus, dass die ursprüngliche Geburt - die des Naturzustandes wiederhergestellt wird; und dass, da jeder ursprünglich als Mensch und dann, ein zweites Mal, sozial als der Inhaber eines bestimmten Status geboren wird, die Freilassung darauf hinausläuft, eine zufällige Geburt zugunsten einer essenziellen solchen auszulöschen. So Marcian im ersten Buch seiner Institutiones: "Manchmal werden in der Sklaverei Geborene dann durch rechtliche Intervention zu von Natur aus Freien (ex post facto iuris interventu ingenui fiunt) « (Dig. 40.11.2; nach Thomas übersetzt). Wenn etwa einem Freigelassenen vom Prinzeps die Gnade gewährt wird, in die Rechte seiner Geburt wiedereingesetzt zu werden (natalibus suis restitutus), dann wird er in die Rechte der Geburt wiedereingesetzt, die allen Menschen ursprünglich zukamen (illis [...] natalibus restituitur, in quibus initio omnes homines fuerunt), und nicht nur in jene seiner eigenen Geburt, bei der er als Sklave geboren wurde (non in quibus ipse nascitur, cum servus natus esset). Von nun an wird der Begünstigte in allen rechtlichen Situationen so betrachtet, als ob er als von Natur aus Freier geboren worden wäre; sein Patron kann nicht mehr sein Erbe antreten ... ${ }^{57}$

Der Kommentar des Marcian versucht, das Paradox aufzulösen, dass einem Sklaven die Gesamtheit jener Rechte wiederzugeben ist, die er satzungsgemäß nicht gehabt haben kann. In jeder restitutio - man denkt selbstverständlich an die diversen Fälle einer restitutio in integrum durch einen Prätor - muss man durch eine Fiktion zulassen, dass der von einem dazu Unfähigen abgeschlossene Rechtsakt keine Existenz hat: Um seine Auswirkungen rückwirkend zu tilgen, stellt der Magistrat die dem Akt vorhergehende Rechtslage wieder her. Ebenso gibt die restitutio in natalibus, die wahrscheinlich von der prätorischen Prozedur einer rückwirkenden Annullierung inspiriert wurde, zu der Annahme Anlass, dass die Geburt als Sklave nicht stattgefunden hat. Die freie Geburt des Menschen wird unterstellt, da sie für das wiedergutmachende Handeln dieser Prozedur erforderlich ist. Es handelt sich hier nicht um eine willkürliche philosophische Darstellung: Der Topos ist Gegenstand einer Re-Investition. Die natürliche Freiheit wird als Kunstgriff verwendet, um institutionelle Freiheit zu schaffen. Eines der Hauptthemen des Naturrechts wird hier in den Dienst einer Technik gestellt: Alles geschieht so, als ob das Recht die Natur modelte. Man fingiert die 
Vorstellung, das Recht setze beiläufig ein natürliches Regime wieder ein, das das Recht zum Verschwinden gebracht habe.

\section{IV.}

Man kann diese Bearbeitung der Idee der Natur schwerlich verstehen, wenn man nicht die praktischen Fälle einbezieht, in denen die Juristen Beziehungen zwischen Institutionen zu bestimmen, Unterschiede in diesen Beziehungen einzuschätzen und ihre Differenzen durch einen Bezug auf ein gemeinsames Modell zu überbrücken haben.

Die Natur wird entweder als ein Relikt präsentiert (wie wir beim Status der res communes oder beim Erwerb der res quae capiuntur gesehen haben), oder aber als ein wiederhergestellter Zustand. Aber sie kann auch für eine Ausweitung des Rechts zur Verfügung stehen. Im Namen der Natur ziehen die Juristen rechtliche Beziehungen in Betracht, die nach dem Vorbild der vom Gesetz geschaffenen Beziehungen gestaltet sind: Man erinnere sich an die den Sklaven zugeschriebene Filiation, mit deren Hilfe man sie gewissen Verboten unterwarf. In einer vergleichbaren Anordnung der Ideen weiten die Juristen die zivilen Verwandtschaftsverhältnisse auf sogenannt natürliche Verwandtschaftsverhältnisse aus, um zu rechtfertigen, dass das Edikt des Prätors sich auch auf die Kognaten, d. h. die Verwandten in mütterlicher Linie, erstreckt, während das Erbrecht eigentlich rechtlich den Agnaten, den Verwandten in väterlicher Linie, vorbehalten ist. ${ }^{58}$ Wenn das Feld der legitimen Institutionen weiter ausgespannt wird, ruft das juristische Denken der Kaiserzeit die Natur als ein stellvertretendes Substrat an. Das Naturrecht bietet in Ermangelung eines gesetzlichen Rechts Ersatz.

Umgekehrt imitiert das Recht die Natur, wenn eine Institution als ihr Doppel präsentiert wird: Die Juristen postulieren, dass sie als Nachbildung eines Werks hergestellt ist, das sie nicht geschaffen haben - so wie die Adoption, die durch den berühmten Aphorismus adoptio enim naturam imitatur definiert wird. ${ }^{59}$ Man beachte die Originalität dieses Vorgehens. Man darf es nicht mit jenen Vorgehensweisen verwechseln, auf die ich im Zusammenhang der natürlichen Prähistorie der öffentlichen Dinge oder der Aneignung der privaten possessio angespielt habe: Denn die Prototypen des ius naturale waren da Zeugen-Figuren, Relikt-Formen, die das Zivilrecht überformt hatte, aber unter seiner strikten Kontrolle fortbestehen ließ. Die Distanz zwischen dem Paradigma und seinen aktuellen Ableitungen entsprach jener zwischen dem versteinerten Ursprung und der durch die zivilen Institutionen bezähmten Zeit. Die Beziehung der Adoption zur nicht-adoptiven Filiation ist vielmehr die der Wahrscheinlichkeit zur Wahrheit.

"Die Adoption«, schreibt Javolenus, "findet nur zwischen Personen statt, zwischen denen die Natur auch (die natürliche Filiation) erlaubt." Was soll das heißen? Der Adoptierende musste in einem Alter sein, das es dem Anschein nach möglich machte, dass er seinen Adoptivsohn gezeugt haben konnte. Nach der Formulierung des Kuriatgesetzes über die Adrogation wurde die Kurienversammlung (Comitia curiata) zu einem Beschluss aufgefordert, wonach $» L$. Valerius der Sohn des L. Titius ist, und dies in jeder rechtlichen Hinsicht, so als ob er von diesem Vater und dessen Ehefrau geboren worden wäre«. Das Pontifikalkollegium, das dieses Verfahren überwachte, überprüfte das Alter der Partner: Der Adrogierte musste schon vesticeps - d.h. geschlechtsreif - sein, und der Adrogierende musste in einem Alter sein, das ihn als 
Erzeuger und Vater eines solchen Sohnes glaubwürdig erscheinen ließ ${ }^{60}$ Hinsichtlich dieser Untersuchung bemerkt Ulpian, dass man der Ansicht war, dass ein Mann unter sechzig Jahren, in seinem fruchtbaren Alter, zu diesem Verfahren zugelassen war, wenn er gute Gründe geltend machen konnte. ${ }^{61}$ Auf alle Fälle musste der Adoptivvater zumindest geschlechtsreif und älter als sein Adoptivsohn sein. ${ }^{62}$ Und um auf Justinian zurückzukommen, der diese Lehre zu Protokoll nehmen wird: »Anerkannt ist, daß ein Jüngerer nicht einen Älteren adoptieren kann. Die Adoption ahmt nämlich die Natur nach, und es wäre ungeheuerlich (pro monstro), wenn der Sohn älter ist als der Vater «. ${ }^{63}$

Die Juristen legten dennoch großen Wert darauf, dass die Distanz zwischen der Institution und ihrem Modell nicht die zwischen Wahrscheinlichkeit und Wahrheit ist (diese irreduzible Differenz zwischen der legitimen, auf die Ehe - und das heißt: die Vaterschaftsvermutung - gegründeten Filiation, und jener, die ein Rechtsakt als Fiktion schafft), sondern vielmehr jene zwischen der Simulation und dem, was wahr ist oder für wahr gilt (da der wahre Vater der ist, der durch die Ehe bezeichnet ist, und kein anderer). Simulation bereits, wenn präzisiert wird, dass der Adoptierende keine Ehefrau haben oder jemals gehabt haben kann: Et qui uxores non habent, filios adoptare possunt (Paul, Dig. 1.7.30; "Auch wer keine Ehefrau hat, kann ein Kind adoptieren«; Behrends [1995], S. 134); so dass in der Klausel »als ob er von irgend jemandem und dessen legitimer Ehefrau geboren wäre«, wie es das Adrogationsgesetz formuliert, die Person der Mutter rein spekulativ ist. Simulation aber auch, wenn gesagt wird, dass genau wie jeder Mann, der keine Ehefrau hat, auch ein - wie der Eunuch zeugungsunfähiger Bürger das Recht zur Adoption und Adrogation besitzt: ${ }^{44}$ Man sieht, wie weit die Grenzen des von der Natur erforderten Anscheins hier verschoben sind. Die Distanz zwischen der als natürlich betrachteten Institution und ihrem Bild ist so groß, dass die Juristen nicht zögern, die Adoption eines Enkels in Erwägung zu ziehen, der von einem nicht existenten Sohn geboren sein soll. Nicht allein das Vorhandensein der Ehefrau ist eine Fiktion, sondern auch die Existenz des Nachkommen, von dem der Adoptierte abstammen soll: »[...] quasi ex filio vel incerto natus sit«, »[...] wie wenn er als Abkömmling eines Sohnes geboren wäre, sei es auch eines unbestimmt gelassenen Sohnes« - von einem unbekannten Dritten, der imaginärerweise den genealogischen Platz des Abwesenden einnehmen würde. ${ }^{65} \mathrm{Um}$ diese doppelt fiktive Konstruktion zu verstehen, lese man diesen Beispielfall, den der Rechtsgelehrte Proculus (zu Beginn des ersten Jahrhunderts) vorstellt: »Hat jemand, der durch seinen Sohn einen Enkel hat, einen anderen an Enkels Statt angenommen, so bin ich nicht der Ansicht, daß mit dem Tode des Großvaters das Rechtsverhältnis der Vaterblütigkeit unter den Enkeln eintritt. Hat er ihn aber so angenommen, daß er auch nach vollem Gesetzesrecht [d. h. durch legitimes Abstammungsrecht, ohne Rekurs auf die Adoption; Anm. Y.T.] sein Enkel sein sollte, nämlich so als ob er ein Abkömmling eines bestimmten Sohnes, zum Beispiel des Lucius, und seiner Ehefrau geboren sei, dann bin ich [was die Vaterblütigkeit angeht; Anm. Y.T.] gegenteiliger Ansicht.« (Proculus, 8 epist. Dig. 1.7.44; Behrends [1995], S. 137.)

Die erste Modalität der Adoption benennt die Person, über die das Band zwischen avus und nepos verläuft, nicht genauer; dieses Glied der genealogischen Kette wird verschwiegen: Das Kind hätte gleichermaßen dem Sohn, von dem der Adoptierende bereits einen Enkel hatte, zugeschrieben werden können, als auch einem anderen, umständehalber erdachten Sohn - irgendeinem incertus -, oder auch einer wirklichen oder fiktiven Tochter. Kurz gesagt: Nichts deutet darauf hin, dass die beiden nepotes Brüder seien und einen gemeinsamen Vater hätten; man kann sie nicht für 
Blutsverwandte halten. Die zweite Modalität präzisiert dagegen die vom Adoptierenden dekretierte Filiation: Der Großvater spricht Lucius, dem legitimen Vater des ersten nepos, die Vaterschaft des zweiten, adoptierten nepos zu.
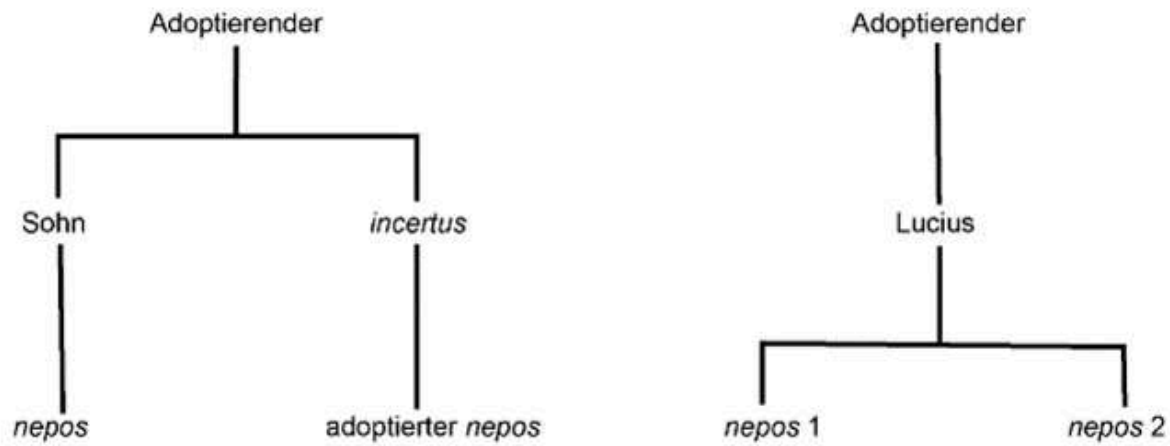

Adoptio naturam imitatur: In den Grenzen des genetisch Wahrscheinlichen nimmt man sich alle Freiheiten, um eine Vaterschaft zu gestalten, die sich - soweit nur irgend denkbar- ganz und gar über die minimalen Bedingungen jeder legitimen Filiation hinwegsetzt: die Ehe und den Respekt der Verwandtschaftsgrade. Denn die Ehe wird vorausgesetzt, selbst wenn es keine Ehefrau gibt; die Mutter wird durch die Fiktion ersetzt, dass der Adoptierende verheiratet sei - und sei er auch Eunuch; dies zeigt, bis zu welchem Punkt die »Natur « den Anschein dessen rechtfertigt, was auf keinen Fall wahr sein kann. Die Verwandtschaftsgrade werden nach freiem Ermessen dekretiert, und dabei werden die Zwischenglieder übersprungen, die in der Natur niemals fehlen. Die juristische Kunst vergrößert so weit als irgend möglich den Abstand zwischen dem Modell und der Institution, die es imitiert: zwischen der Wahrheit und den Kunstgriffen des Rechts. Auf welche Natur wird man jedoch zurückverwiesen, wenn es um Normen geht, die so ausgearbeitet sind wie jene, die ein Kind mit seinem Vater verbinden? Welchen Elementen der Filiation, über die die Adoption geregelt wird, sprechen die Juristen den Wert der Beispielhaftigkeit zu?

41 Um mit dieser Analyse weiterzukommen, muss man einen zweiten Merksatz in Erinnerung rufen, der sich offensichtlich zu dem vorherigen komplementär verhält: "[...] damit nicht die Wahrheit durch eine Nachahmung der Natur verdunkelt wird", schreibt Papinian hinsichtlich der Adoption: ne imagine naturae veritas adumbretur. Das Doppel kann das Original nicht zum Verschwinden bringen. Um diese Formel nach neuplatonischem Muster $\mathrm{zu}$ verstehen und um aufzuklären, bei welchem Grad juristischer Ausarbeitung das institutionelle Modell angesiedelt ist, von der sich die Kunsthandwerker des Rechts inspirieren lassen, ist es immer noch am einfachsten, die praktische Schwierigkeit zu untersuchen, die Papinian aufzulösen versucht, wenn er der Natur ihre imago gegenüberstellt:

»Ich habe gesagt, daß einem Sohn eine früher angeordnete Enterbung schadet, wenn ihn der Vater, nachdem er ihn aus der Hausgewalt entlassen hatte, durch Adrogation wieder adoptierte. Denn man ist sich einig, fast in der gesamten Rechtsordnung so zu verfahren, daß ein Sohn niemals als der Adoptivsohn seines wahren Vaters angesehen wird, damit nicht die Wahrheit durch eine Nachahmung der Natur 
verdunkelt wird, so daß also anzunehmen ist, er habe sich nicht [erstmals] in die Hausgewalt begeben, sondern sei in sie zurückgekehrt. Und was den vorliegenden Fall angeht, meine ich, daß es nicht viel ausmacht, daß der Vater den enterbten Sohn an Enkels Statt durch Adrogation adoptiert hat« (Dig. 28.2.23 pr.; Knütel (2012), S. 21; Hervorhebung Y.T.)

Ein Vater enterbt seinen Sohn, emanzipiert ihn dann und adoptiert ihn schließlich durch Adrogation (ein notwendiges Vorgehen, da der Sohn eine Person sui iuris geworden war). Nun stellt sich die Frage: Wie steht es um die Erbrechte dessen, der der Reihe nach enterbt, emanzipiert und adoptiert wurde? Die Antwort auf diesen praktischen Fall hängt von der Vorstellung ab, die der Jurist von der Beziehung zwischen "wahrer" (sich also auf die Regel pater is est quem nuptiae demonstrant gründender) und adoptiver Filiation - zwischen Natur und institutioneller Fiktion hat. Man mag zunächst denken, dass die nachfolgende Adoption, nachdem das "natürliche« Band zerschnitten war, ein neues Band knüpft, das gänzlich durch den Rechtsakt geschaffen ist. Nach dieser Hypothese tritt der zuvor enterbte Sohn nur aufgrund der Filiation qua Adoption wieder in seinen Erbanspruch ein; er wird ein anderer Sohn, der mit allen Rechten versehen ist, die sein neuer Vater ihm noch nicht genommen hat. Kurz: Alles hat von vorne begonnen. Aber man kann auch zu dem gegenteiligen Schluss gelangen: Wenn nämlich zwischen zwei Personen nacheinander zwei [unterschiedliche] Filiations-Beziehungen geknüpft werden - die erste aufgrund der Ehe, die zweite, nach dem Zwischenspiel einer Trennung, durch Adoption -, besteht das ursprüngliche Band weiter, oder ist vielmehr erneuert. Die Rückkehr zum Vater durch die Adoption lässt die Rechte des Vaters als niemals unterbrochen und nicht einmal als vorübergehend ausgesetzt erscheinen; die Emanzipation und die durch diese verursachte rechtliche Vakanz sind zugunsten einer Erneuerung des ursprünglichen Bandes rückgängig gemacht worden. Dank dieser fiktiven Manipulation ist das Recht der väterlichen Gewalt aber immer noch dasselbe: Die vorhergehende Enterbung bleibt bestehen und schadet dem Sohn immer noch.

Diese ganze juristische Argumentation stützt sich auf die Regel ne imagine naturae veritas adumbretur. Was aber ist diese naturae veritas? In erster Linie ist sie die Position, die sich aus einer legitimen Filiation - und das heißt: aus einer institutionellen Beziehung - ergibt; in zweiter Linie ist sie das Bündel von Rechten, die über dieser Position errichtet wurden.

Wenn er die von Papinian ausgearbeitete kasuistische Lösung referiert, nimmt Ulpian eine Abkürzung, um die Essenz dieser Natur zu ergreifen: »Papinian verfügt, dass die Rechte der Natur weiterhin stärker sind (iura naturalia in eo praevalere): Daher schadet die Enterbung dem Sohn« (Dig. 37.4.8.7 [korr. N.G.]; nach Thomas übersetzt; N.G.). Die iura naturalia sind nichts anderes als die Institution einer Vaterschaft, die neben anderen Attributen ihrer Gewalt auch das Recht umfasst, den Sohn zu enterben. In diesem Sinne läuft die "Nachahmung der Natur" darauf hinaus, eine rechtliche Beziehung zu wiederholen, die das Recht ursprünglich geknüpft hatte. Der Rechtsakt lässt das unterbrochene Band mit einigem zeitlichen Abstand wiederaufleben; dieser Akt tritt hinter seiner Wirkung zurück, die sich auf das wiederhergestellte ursprüngliche Recht bezieht. Was der Kunstgriff herstellt, wird einer wieder zutage tretenden Natur zugesprochen (die nichts anderes als eine Institution ist): Ebenso würde die "Wiedereinstellung in die Rechte der Geburt« die rechtliche Aufhebung der Freiheit annullieren und damit dieser wiedergefundenen Freiheit - in den antiken Stadtgemeinden eine rechtliche Institution wie kaum etwas sonst - den Weg ebnen. 
Diese Überlegungen wurden allein von Operationen der Kasuistik ausgehend angestellt: Es sind offensichtlich gedankliche Operationen. Man entdeckt dort, wie mir scheint, dass es für die Juristen keine andere Natur gibt als jene, die sie selbst geschaffen haben. Die Kohärenz des institutionellen Diskurses bringt der Natur ihren - höchst originellen - Status als Institution ein.

\section{BIBLIOGRAPHIE}

Arnaud, A.-J. (1968): „Réflexion sur l'occupatio«, Revue historique des Facultés de droit 46, S. 183210.

Castello, C. (1968): Sull'età dell'adottante e dell'adottato in diritto romano, Mailand: Giuffrè.

Charbonnel, N. / Morabito, M. (1987): „Les rivages de la mer: droit romain et glossateurs«, Revue historique de droit français et étranger 65, S. 23-44.

Dalla, D. (1978): L'incapacità sessuale in diritto romano, Mailand: Giuffrè.

Daube, D. (1959): »Doves and Bees«, in: Institut de droit romain (Paris) (Hg.), Droits de l'antiquité et sociologie juridique. Mélanges Henri Lévy-Bruhl, Paris: Sirey, S. 63-75.

Dell'Oro, A. (1962): »Le res communes dell'elenco di Marciano e il problema del loro fondamento giuridico«, Studi Urbinati 31, S. 237-290.

Duff, A. M. (1928): Freedmen in the Early Roman Empire, Oxford: Clarendon Press.

Fanizza, L. (1982): Giuristi crimini leggi nell' età degli Antonini, Neapel: Jovene.

Kaser, M. (1971): Das römische Privatrecht, München: C.H. Beck.

Kantorowicz, E. (1961): »The sovereignty of the artist: A note on legal maxims and Renaissance theories of art«, in: M. Meiss (Hg.), De artibus opuscula XL: Essays in Honor of Erwin Panofsky, New York: New York University Press, S. 267-279.

Lanata, G. (1984): Legislazione e natura nelle novelle giustinianee, Neapel: Edizioni scientifiche italiane.

Magdelain, A. (1978): La loi à Rome. Histoire d'un concept. Paris: Les Belles Lettres.

Mantello, A. (1984): „Un illustre sconosciuto tra filosofia e prassi giuridica. Eufrate D’Epifania«, in: V. Giuffrè (Hg.), Sodalitas: Scritti in onore di A. Guarino 2, Neapel: Jovene, S. 963-995.

Millar, F. (1977): The Emperor in the Roman World, London: Duckworth.

Moreau, Ph. (1981): Clodiana religio, Paris: Les Belles Lettres.

Nicolet, C. (Hg.) (1990): Insula sacra: La loi Gabinia Calpurnia de Délos, Rom: École française de Rome.

Renoux-Zagamé, M.-F. (1987): »La disparition du droit des gens classique«, Revue historique des Facultés de droit 4, S. 23-53.

Rotondi, G. (1992): Leges publicae populi Romani. Elenco cronologico con una introduzione sull'attivita legislativa dei comizi romani. Hildesheim: Olms. 
Russo Ruggieri, C. (1990): La datio in adoptionem. I: Origine, regime giuridico e riflessi politicosociali in età repubblicana ed imperiale, Mailand: Giuffrè.

Serrao, F. (1974): Classi partiti e legge nella repubblica romana, Pisa: Pacini.

Voci, P. (1952): Modi di acquisto della proprietà: corso di diritto romano, Mailand: Giuffrè.

Weiss, H. G. (1955): Das Willensmoment bei der occupatio des römischen Rechts, Marburg.

\section{Übersetzungen der lateinischen Quellen}

Behrends, O. et al. (Hg.) (1997): Corpus Iuris Civilis, Bd. I: Institutionen, 2. verb. Aufl., Heidelberg: C. F. Müller.

Behrends, O. et al. (Hg.) (1995): Corpus Iuris Civilis, Bd. II: Digesten 1-10, Heidelberg: C. F. Müller.

Behrends, O. et al. (Hg.) (1999): Corpus Iuris Civilis, Bd. III: Digesten 11-20, Heidelberg: C. F. Müller.

Knütel, R. et al. (Hg.) (2005): Corpus Iuris Civilis, Bd. IV: Digesten 21-27, Heidelberg: C. F. Müller.

Knütel, R. et al. (Hg.) (2012): Corpus Iuris Civilis, Bd. V: Digesten 28-34, Heidelberg: C. F. Müller.

[Diese zweisprachige Ausgabe des C.I.C. soll fortgesetzt werden, seit 2012 ist aber kein weiterer Band mehr erschienen; A.d.Ü.]

Die lateinischen Texte des C.I.C. findet man auch online, z. B. hier: https://droitromain.univgrenoble-alpes.fr.

Codex Justinianus, übers. v. Rudolf Haller, online verfügbar unter: http://www.opera-

platonis.de/CI/Codex.html.

Cicero (1974): Über die Gesetze, in: ders., Staatstheoretische Schriften, lateinisch und deutsch von Konrat Ziegler, Berlin: Akademie-Verlag, S. 211-329.

Cicero (1999): Der Staat. De re publica. Lateinisch-deutsch, übers. v. Karl Büchner, Düsseldorf: Artemis und Winkler.

\section{NOTES}

1. Ulpian, Digesten 1.1.1.3 (im Folgenden werden die Digesten mit D. abgekürzt).

2. Florentin, Inst. 9, D. 1.5.4; Marcian, Inst., D. 1.8.2; Ulpian, Inst. 1, D. 1.1.4; Hermegonian, Epitome Iuris 1, D. 1.1.5. Das Thema der natürlichen ungeteilten Gemeinschaft war schon von Cicero in De officiis 1.7.21 erörtert worden.

3. Florentin, Inst. 1, D. 1.1.3: ut vim atque iniuriam propulsemus (»daß wir uns gegen Gewalt und Unrecht wehren«; Behrends (1995), S. 92) ist ein Satz des Naturrechts, wie es die Fortsetzung dieser Passage zeigt, wo das Verbot des Mordes mit einer natürlichen Verwandtschaft zwischen den Menschen begründet wird. Vgl. Ulpian, D. 43.16.1.27: „Vim vi repellere licere Cassius scribit idque ius natura comparatur [...]

4. D. 1.1.5; Justinian, Inst. 1.2.2. Dieses ius gentium umfasst auch Regeln des internen Privatrechts (z. B. die stipulatio iuris gentium; Gaius 3.93) ebenso wie des internationalen öffentlichen Rechts (Pomponius, D. 50.7.18: die Immunität der ausländischen Gesandten). Für die fortschreitende Trennung dieser beiden Aspekte in der modernen Rechtslehre vgl. Renoux-Zagamé (1987), S. 2353.

5. Inst.1.1 Vormundschaft: Gaius 1.189 (Justinian, Inst. 1.20.6). Traditio: Gaius 2.66; D. 41.1.9.3. Rückerstattung einer nicht gerechtfertigten Zahlung: Pomponius, D. 12.6.14 (Paul, D. 12.6.15 pr. 
korr. N.G.). Ausgleich einer unbilligen Bereicherung: Pomponius, D. 50.17.206. Freier Widerruf dessen, was in einer Notlage eingeräumt wurde: Ulpian, D. 43.26.2.2 und viele weitere.

6. Ulpian, D. 1.1.6. [korr. N.G.].

7. Cicero, De legibus $1.17-18 ; 1.28 ; 1.42-44$.

8. Cicero, De republica 3.22.33.

9. Cicero, De legibus, 1.35 (vgl. 1.20: repetam stirpem iuris a natura (»so will ich die Wurzel des Rechts in der Natur zu finden suchen«, Cicero [1974], S. 225); 1.28: natura constitutum esse ius (»daß das Recht [...] in der Natur begründet ist«, Cicero [1974], S. 229); 1.34: ius in natura esse positum (»daß das Recht aus der Natur hervorgegangen ist«, Cicero [1974], S. 233), etc.). Die Thematik des Naturrechts erscheint zuerst in den Rechtspartituren bei den Rhetoren: Rhetorica ad Herennium 2.13; de inventione $2.65 \mathrm{ff}$.

10. Cicero, De legibus, 1.44 .

11. Florentin, D. 1.5.4; Ulpian D. 50.17.32 Ulp. 43 ad Sab. (Korrektur der Quellenangabe durch H.M.); Justinian, Inst., 1.2.2 (servitutes, quae sunt iuri naturali contrariae [»die dem Naturrecht widersprechen « [Behrends (1997), S. 3]).

12. Die republikanischen Gesetze enthalten oft eine Ausnahme-Klausel, durch die das frühere sakrosankte Recht (d.h. die Verträge und die auf einen Eid sich gründende tribunizische Verfassung) bewahrt werden: Valerius Probus, 3.13; Cicero, pro Balbo 32; de domo 106; Lex Calpurnia Gabinia von Delos 1.37 (in: Nicolet [1980], S. 10). Dieser exceptio (ein Terminus, der sich aus dem Gebrauch von excipio bei Cicero, op. cit., ergibt) stellt sich die sanctio entgegen, eine Klausel der Straffreiheit, durch die das Recht sich gegen das Verbot schützt, ein früheres Gesetz abzuschaffen (Cicero, ad Atticum 3.23.2; lex de imperio Vespasiani), oder eine Klausel der Unaufhebbarkeit, die es im Gegenteil vor einer späteren Aufhebung schützt: Jedes Gesetz lehnt sich gegen die ihm vorausgehenden oder nachfolgenden Gesetze auf, außer wenn es sich ausdrücklich, durch eine exceptio, vor dem ius sacro sanctum auslöscht. Zu diesen Klauseln vgl. Serrao (1974), S. 82 f.; Magdelain (1978), S. 59 f. und das Kap. 4. In der Kaiserzeit herrscht, wie man weiß, das Prinzip princeps legibus solutus vor, das von Ulpian (D. 1.3.31) formuliert wurde, aber seinen ersten Ausdruck im lex de imperio findet - der Verfassungs-Charta des Prinzipats, die für jeden neuen Kaiser erneuert wird (lex de imperio Vespasiani, 1.25, Fontes Iuris Romani AnteJustiniani, I, S. 156: utique quibus legibus [...] solutus sit). Dennoch wiesen Septimius Severus und Caracalla in ihren Verordnungen häufig darauf hin, dass legibus soluti sumus, attamen legibus vivimus (Just. Inst. 2.17.8) [»[...] sind wir auch von den Gesetzen befreit, leben wird doch nach den Gesetzen« [Behrends (1997), S. 101]; vgl. Codex Just. 6.23.3 (a. 232): licet enim lex imperii sollemnibus iuris imperatorem solverit, nihil tamen tam proprium imperii est, ut legibus vivere (»Denn obwohl das Gesetz den Kaiser von den Förmlichkeiten des Rechts befreit, so ist ihm doch nichts so gemäß, als nach den Gesetzen zu leben«). Ein Prinzip der Selbstbeschränkung, das in einer Constitutio von 429 glanzvoll bekräftigt wird, Codex Just. 1.14.4 [korr. N.G.]: Digna vox maiestate regnantis legibus alligatum se principem profiteri: adeo de auctoritate iuris nostra pendet auctoritas. Et re vera maius imperio est submittere legibus principatum. Et oraculo praesentis edicti quod nobis licere non patimur indicamus. (»Der Majestät eines Herrschers ist der Ausspruch würdig, wodurch sich derselbe an die Gesetze gebunden erklärt und deshalb hängt auch von dem Ansehen des Rechts Unser eigenes ab. Und wirklich deutet es mehr Größe an, die Gewalt des Herrschers dem Gesetz unterzuordnen, als unbeschränkt zu herrschen. Durch den Ausspruch des gegenwärtigen Edictes verkündigen Wir allgemein, was Wir Uns selbst nicht erlauben dürfen« [Übers. R. Haller]). Es gibt keine andere Grenze für das Recht als das Recht selbst: Keine Normenhierarchie - und insbesondere keine zugunsten des Naturrechts - wird anerkannt. Die Juristen des Mittelalters interpretieren diese Texte ganz anders. Denn zu sagen, dass der Fürst legibus solutus ist, wird einerseits zu einem Eingeständnis, dass er an die Normen des ius naturale gebunden ist; in dieser Eigenschaft kann er durch seine Anordnungen seinen Untertanen keinen Schaden zufügen (Azon, Summ. Cod. 1.22.2: si tamen laedatur in eo, quod et competit de jure naturali, nullum est [rescriptum]; 
vgl. Hugolinus, Dissensiones dominorum, 5: valeant [rescripta] nisi sunt juri naturali contraria. Andererseits ist der Fürst im Blick auf die Gesetze frei, nicht aber im Blick auf die Verträge, die er mit seinen Vasallen abgeschlossen hat, denn der Vertrag verpflichtet aufgrund des ius gentium, d.h. des Naturrechts. Bartole, comm. in cod. 1.14.4; Balde, Super feudis (Ausg. Lyon 1542, fol. 19: Deus subjecit ei leges, sed non subjecit ei contractum ex quibus obligatus est, ut notat digna vox; Cynus, comm. in cod. (Ausg. Frankfurt 1578, fol. 26 R) 1.14.21: contractus principis est lex. Nichts bezeugt die Originalität der mittelalterlichen Gelehrtenkultur besser als die Tatsache, dass sie den Despotismus des Gesetzes digna vox begrenzt haben, indem sie dieses mit dem im Naturrecht verankerten Prinzip des Respekts der Verträge verknüpften.

13. Tryphoninus, D. 1.5.15 (vgl. D. 5.1.28.2 [eher 5, N.G.]: Die Natur gestattet es nicht, die Zahl der postumen Kinder zu kennen, die noch geboren werden.

14. Siehe im Text weiter unten.

15. Modestin, D. 38.10.4 pr. [korr. N.G.]: »Wenn man die natürlichen Verwandtschaftsbeziehungen in unserem Recht behandelt, ist es schwierig, über den siebten Grad hinauszugehen: Denn die Natur erlaubt es nicht, dass sich das Leben unserer Verwandten über diesen Grad hinaus verlängert« (übers. nach Thomas). Dieser Text geht von der Annahme aus, dass alle Verwandtschaftsgrade zur selben Zeit lebten: Die Natur stellt ein Hindernis für die Lebensdauer dar. Ego kann zu gleicher Zeit seinen Neffen oder seine Nichte dritten Grades (das Kind seines Cousins/seiner Cousine zweiten Grades) und den Urgroßvater, von dem sie beide abstammen, kennen: So können vier Generationen gleichzeitig existieren. Diese GenerationsNorm wird bei Cicero, De officiis, 1.17.54 ausgeführt; vgl. Sententiae Pauli 4.11.8: "Die Grade der Verwandtschaft wurden im Erbrecht auf sieben festgesetzt, da die Natur es jenseits dieser Grenze nicht erlaubt, die Namen der Erben zu finden, und es auch nicht erlaubt, das eigene Leben in seinen Erben verlängert zu sehen.«

16. D. 5.1.12.2.

17. D. 45.1 .35 , pr.-1.

18. D. 23.2.14.2: serviles quoque cognationes in hoc iure observandae sunt [...] nec volgo quaesitam filiam pater naturalis potest uxorem ducere, quoniam in contrahendis matrimoniis naturale ius et pudor inspiciendus est. (»Auch die Blutsverwandtschaft unter Sklaven ist in diesem Rechtsgebiet zu beachten. [...] Daher kann ein leiblicher Vater auch seine nichteheliche Tochter nicht zur Ehefrau nehmen, weil für die Regelungen für die Eingehung der Ehe auch auf das Naturrecht und das Schamgefühl Rücksicht zu nehmen ist«; Knütel [2005], S. 143).

19. Pomponius, 5 ad Sabinum, D. 23.2.8: quia hoc ius moribus non legibus introductum (»Diese Bestimmung ist durch die Sitte, nicht durch Gesetze eingeführt worden« [Knütel (2005), S. 141]; hinsichtlich des Inzests unter Sklaven); aber für den Inzest unter Bürgern berufen sich andere Texte entweder auf den mos (Titus Livius, Fragment des 20. Buchs, Hermes 4, S. 372) oder auf die leges (Tacitus, Annales, 12.8). Eine Constitutio Diokletians präsentiert im Jahr 295 die römische Tradition der Heiratsverbote weiterhin in der Terminologie der Legalität (Mosaicarum et Romanarum legum collatio 6.4.1). Diokletian betrachtete diese Verbote als vom Recht geboten (disciplina iuris veteris; nuptiae [...] Romano iure permissae; [...] sanctitas legum [...]) und als den Barbaren unbekannt (die Verwandtenehen waren ebenso ferarum ritu als barbaricae immanitatis ritu). Man denke aber auch an Pauls Sabinus-Kommentar in D. 45.1.35.1: »Item quod leges fieri prohibent [...] cessat obligatio, veluti si sororem nupturam sibi aliquis stipuletur [...].« Gewiss wird der Inzest gelegentlich als nefas erachtet: Doch diese verschärfte Formulierung des Verbots bedeutet nicht, dass es eine von den Römern als religiös betrachtete Quelle habe (eine Gegenposition vertritt Moreau [1981], S. 86). Nefas wird sehr häufig ohne Zusammenhang zum religiösen Frevel gebraucht (so in D. 1.1.3: hominem homini insidiari nefas esse (»daß es frevelhaft ist, wenn ein Mensch dem anderen nach dem Leben trachtet«; Behrends [1997], S. 92).

20. D. 1.1.2. 
21. D. 2.4.4.3. Vgl. Paul, D. 2.4.5-6: über die natürlichen Verwandtschaftsverhältnisse der Sklaven; Venuleius, D. 48.2.12.4 [korr. N.G.] (zum Mord an Verwandten); Ulpian, D. 37.15.1.1 (Pflicht zur pietas); Paul, D. 23.2.14.2 (Inzest).

22. Ulpian, D. 37.15.1.1-2 [korr. N.G.].

23. D. 48.2.12.4. Vgl. Fanizza (1982), S. 63 und 77. Durch eine vergleichbare Ausweitung des Begriffs der Verwandtschaft versucht Florentin, wie mir scheint, das Verbot des Mordes zu denken. (1 Inst., D. 1.1.3: et cum inter nos cognationem quandam natura constituit, consequens est hominem homini insidiari nefas esse [»Und da die Natur unter uns so etwas wie eine Verwandtschaft begründet hat, folgt daraus, daß es frevelhaft ist, wenn ein Mensch dem anderen nach dem Leben trachtet«; Behrends 1995; S. 92]). Man wird bemerken, dass der qualifizierte Tatbestand, »einem Menschen Fallstricke zu stellen«, aus der lex Cornelia de sicariis übernommen ist, einem Gesetz gegen die Wegelagerei (und nicht gegen Mord und Totschlag). Der römische Begriff des homicidium kommt erst spät auf: Er wird zwischen dem ersten und dem zweiten Jahrhundert unserer Zeitrechnung durch einen Neologismus geprägt, der sich am Modell des parricidium orientiert. Wenn der Mord als ein Gattungsbegriff gedacht wird, der die besonderen Fälle der lex de sicariis unter sich vereint, so sieht man hier, dass der Jurist ein verwandtschaftliches Band zwischen allen Menschen postuliert: Der Mord ist ein universalisierter Verwandtenmord.

24. In der Gesetzgebung Justinians sind der Inzest und die Homosexualität "wider die Natur«. Vgl. zu den naturrechtlichen Grundlagen des Rechts der Novellae das schöne Buch von Lanata (1984), insbesondere S. 165-187.

25. Vgl. Ambrosius, ep. 73.2: esse autem legem naturalem in cordibus nostris etiam apostolus docet, qui scripsit quia plerumque ret gentes naturaliter ea, quae Legis sunt, faciunt, et cum Legem non legerint, opus tamen Legis scriptum habent in cordibus suisı. Augustinus, Contra Faustum 19.2 setzt dem hebräischen Gesetz »von Sünde und Tod« gemäß dem Hl. Paulus (Römer 8,2) entgegen, aliud vero Gentium, quod naturale vocat: entes enim, inquit; oder naturaliter quae legis sunt faciunt; et ejusmodi legem non habentes, ipsi sibi sunt lex, qui ostendent opus legis scriptum in cordibus suis. Das natürliche Gesetz, das bei Ambrosiaster (Comm. in Ep. ad Rom. 3.20)

die von Moses übermittelten Gebote umfasste, kommt von nun an ohne diesen formellen Vermerk aus (siehe dazu auch Hilaire de Poitiers, Tract. in Ps., 118). Diese Auffassung wird in Justinians Institutiones (1.2.11) aufgegriffen: naturalia quidem iura, quae apud omnes gentes peraeque servantur, divina quade providentia constituta semper firma atque immutabilia permanent. ("Die naturrechtlichen Rechtssätze aber, die bei allen Völkerschaften gleichermaßen befolgt werden, sind von wahrhaft göttlicher Vorsehung geschaffen worden und bleiben immer gültig und unwandelbar«; Behrends [1997], S. 5.) Die Zuschreibung der Institutionen des ius gentium zum ius naturale geschieht erst spät (vgl. dazu auch Isidor, Etymologiae 5,4).

26. Zu diesem Text (D. 1.1.1.1) vgl. den Aufsatz von Mantello (1984), S. 978 f., der den Bezug auf die »wahre Philosophie« übermäßig historisiert, da diese schon ein ciceronianisches Thema gewesen sei (de oratore 1.195).

27. Ulpian, D. 1.1.1.2. privatum ius tripertitum est: collectum etenim est ex naturalibus aut gentium aut civilibus praeceptibus (»Das Privatrecht besteht aus drei Teilen. Denn es setzt sich aus Vorschriften des Naturrechts, des Völkergemeinrechts und des Zivilrechts zusammen«; Behrends [1995], S. 92.) Höchstwahrscheinlich hatten sich die Institutiones von Florentin und Marcian diesen Plan bereits zu eigen gemacht.

28. Neratius, D. 41.1.14 [korr. N.G..]: quae primum a natura prodita sunt et in nullius adhuc dominium pervenerunt.

29. Marcian, Inst. 3, D. 1.8.2; Justinian, Inst. 2.1 pr., 2.1.1, 2.1.4 und 2.1.5; Neratius, D. 41.4.14; Gaius, D. 41.1.7.4.

30. Siehe unten.

31. Über die res communes (im Anschluss von Marcian, D. 1.8.2 pr.) Dell'Oro (1962), S. 255 f. Unter Augustus stellt Labeo eine - unvollständige - Liste der loca publica auf: ad areas et ad insulas et ad 
agros et ad vias publicas itineraque publica pertineat, D. 43.8.2.3; vgl. Ulpian, D. 43.8.2.9: in campo publico [...] vel in publico balineo [...] aut in theatro [...]; die öffentlichen Straßen sind Gegenstand vorsichtiger Definitionen (D. 43.8.2.21-22), ebenso wie die öffentlichen Wasserläufe und ihre Ufer (D. 43.12 bis D. 43.15). Über die gleichbedeutende Bestimmung res universitatis, die den gemeinsamen Besitz »aller Bürger« (universi) betont, vgl. Marcian, D. 1.8.2 pr.: quaedam naturali iure communia sunt omnium, quaedam universitatis [d. h. publicae] (»Manche Sachen stehen nach Naturrecht allen zu, manche einer Gesamtheit [...]«; Behrends [1995], S. 138); vgl. D. 1.8.6.1: Universitatis sunt, non sin gulorum veluti quae in civitatibus sunt [...] communia civitatium (»Der Gesamtheit, nicht einzelnen Menschen gehört das, was sich in den Städten befindet [...] und was es sonst an gemeinschaftlichen Dingen in den Stadtgemeinden gibt«; Behrends [1995], S. 139); Gaius, Inst. 2, D. 1.8.1: quae publicae sunt [...] ipsius enim universitatis esse creduntur (»Von denjenigen Sachen, die öffentliche sind, nimmt man an, [...] daß sie der Gesamtheit gehören«; Behrends [1995], S. 138), vgl. Justinian, Inst. 2.1.1.6. Universitas wird gelegentlich im Sinne von "Stadtgemeinde« verwendet: D. 3.4.3; D. 3.4.7.1.

32. Vgl. Marcian, D. 1.8.2 pr. (siehe vorige Anmerkung); siehe auch Justinian, Inst. 2.1 pr.

33. D. 18.1.34.1.

34. So Celsus, D. 43, 8, 3, 1 Cels. 39 dig. (maris communem usum omnibus hominibus); D. 47.10.13.7 Ulp. 57 ad ed. (publica) (jeweils korr. H.M.); D.39.2.24, pr. Ulp. 81 ad ed. (publica) Zu den begrifflichen Divergenzen vgl. Charbonnel / Morabito (1987), S. 24 f., S. 30 (Anm.).

35. Diese Verbote beschützen ausschließlich das Regime der res publicae (D. 43.3 bis 43.14). Die Verweigerung des freien Zugangs zum Meer gibt zu privatrechtlichen Klagen Anlass (D. 43.8.2.9), und die missbräuchlichen Bauvorhaben können mit einem "nützlichen« Verbot beantwortet werden (D. 43.8.2.8) [jeweils korr., N.G.].

36. D. 1.8.4; D. 39.1.1.18; D. 41.1.30.4 [korr. N.G.]; D. 41.1.50 [korr. N.G.]; Justinian, Inst. 2.1.1-5 [korr. N.G.].

37. Papinian, D. 41.3.45: praescriptio longae possessionis ad optinenda loca iuris gentium publica concedi non solet.

38. Neratius, D. 41.1.14.

39. D. 1.8.6. pr. Es sei hier angemerkt, dass das Regime der res sacrae es genau umgekehrt hält: Wenn ein locus öffentlich den Göttern geweiht ist, löscht die Zerstörung des Heiligtums den Status des Bodens, definitiv sacer zu sein, nicht aus (Marcian, D. 1.8.6.3). Was Privatleute der Natur abgerungen haben, ist ihr einstweiliger Besitz - was die Stadtgemeinde öffentlich ihrem Territorium einschreibt, erhält dagegen einen definitiven Status.

40. Neratius, D. 41.1.14 pr. [korr. N.G.]: nam litora publica non ita sunt, ut ea, quae in patrimonio sunt populi, sed ut ea, quae primum a natura prodita sunt et in nullius adhuc dominium pervenerunt; der weitere Text vergleicht die Besitznahme dieser gemeinschaftlichen res nullius mit der der wilden Vögel und Fische, »die, sobald sie gefangen sind, in den Besitz desjenigen übergehen, in dessen Herrschaft sie gefallen sind«. Vgl. Pomponius, D. 41.1.30.4: »Wenn ich eine Insel im Meer errichte, wird sie sogleich mein Eigentum, weil das, was niemandem gehört, Eigentum des ersten Besitznehmer wird (quoniam id, quod nullius sit, occupantis fit)« [übers. nach Thomas].

41. Wir haben (oben in Anm. 40, unten in Anm. 43) gesehen, dass die res nullius in erster Linie der Natur angehören. Aber es gibt auch seitens der Polis »Dinge, die in niemandes Besitz sind «, res nullius in bonis; dies sind die den Göttern geweihten res (die res sacrae), die Stadtmauern, die zu durchbrechen verboten ist (res sanctae), und die res publicae oder universitatis, die Miteigentum aller cives sind; vgl. Gaius 2.9 und 2.11; Marcian, D. 1.8.6.2.; Justinian, Inst. 2.1.7.

42. D. 1.8.10.

43. Zur Definition der wilden Tiere als res nullius vgl. Gaius 2.66; Neratius, D. 41.1.14; PseudoGaius, D. 41.1.3 pr; Justinian, Inst. 2.1.12. Zur occupatio der Tiere vgl. Daube (1959), S. 63 f. 
44. Das Tier ist von Natur aus "frei« (siehe unten), d.h. es ist vor seiner Besitznahme jedem Recht entzogen. Zur Verwirklichung des subjektiven Rechts durch die erste Besitznahme vgl. den (unten zitierten) Text des Neratius.

45. Die Theorie der Titel des Besitzerwerbs ist am klarsten in Voci (1952), S. 172 f. dargestellt.

46. So auch die Erörterungen des Pseudo-Gaius (D. 41.1.1) über die Priorität der »mit dem Menschengeschlecht « auf die Welt gekommenen Formen des Naturrechts im Vergleich zu den zivilen Formen des Erwerbs, und über die entscheidende, an erster Stelle behandelte Rolle der Besitznahme in diesen Formen des Naturrechts.

47. Gaius, Inst. 2.67; D. 41.1 .5 pr. [korr. N.G.]

48. D. 41.1.5.1. [korr. N.G.]

49. Paul, D. 41.2.3.21; D. 41.10.2.

50. Ulpian, D. 41.10.1; Paul, D. 41.2.3.4. Dieser doppelte (generische und spezifische) Titel ist von der Frage des »Putativtitels« unabhängig, und dies entgegen der Darstellung bei Voci (1952), S. 129 f. und Kaser (1971), S. 422.

51. D. 41.10.2. Zum Begriff der genera possessionis, vgl. Quintus Mucius Scaevola, in D. 41.2.3.21.

52. [Das Zitat ist eine gekürzte Wiedergabe von Dig. 41.1.5.2-4; A.d.Ü.]

53. Gaius, Inst. 2.68; D. 41.1.5..$^{5-7}$.

54. Gaius, Inst. 2.67.

55. Zitiert bei Ulpian, D. 41.1.44 (übers. nach Thomas).

56. Papinian, Frag. Vat. 226: ius anulorum ingenuitatis imaginent praestat; vgl. Diokletian, C.I.C. 9.21.1: quoad vivunt imaginem, non statum ingenuitatis obtinent. (»Denn dann erhalten sie auf Lebenszeit einen Anteil an der Freigeborenheit, nicht aber diesen Rechtsstand«, Übers. R. Haller. Imaginem meint aber wohl eher das Bild, die Simulation der Freigeborenheit, als einen "Anteil« an ihr; N.G.) Zur lex Visellia vgl. Rotondi (1992), S. 464.

57. Dieser Text ist meines Wissens in den Arbeiten über das Naturrecht nicht ausgewertet worden: wahrscheinlich, weil das Wort »Natur« dort nicht vorkommt.

58. Gaius 1.156; Modestin, D. 38.10.4.2.; Paul, D. 38.10.10.4. Dieser Begriff der natürlichen Verwandtschaft ist schon bei Plinius dem Jüngeren (Panegyrikus 39.2) bekannt, aber - als spezifische Kategorie zumindest - noch nicht bei Cicero (in De legibus 1.23 geht es um das Band der Agnation, das in der Natur die Menschen mit den Göttern verbindet).

59. Justinian, Inst. 1.11.4. Zum Schicksal dieses geflügelten Wortes im Mittelalter vgl. Kantorowicz (1961), S. 267 f.

60. Aulus Gellius, Noctes Atticae 5.19.6-9; Javolenus, D. 1.7.16.

61. D. 1.7.15.2.

62. Modestin, D. 1.7.40.1. Der Vermerk id est decem et octo annis eum praecedere debet (»er muß um achtzehn Jahre älter als der andere sein«, Behrends [1995], S. 136) wird allgemein als Interpolation angesehen.

63. Justinian, Inst. 1.11.4 (Behrends [1997], S. 20). Auch andere Regeln gründen sich auf diese biologische Ordnung der Natur: So etwa, dass die Nachfahren die Verwandten in aufsteigender Linie beerben, und nicht umgekehrt (D. 38.6.7.1), oder dass der Sohn beim Tod seines Vaters die väterliche Gewalt über seinen eigenen Sohn erlangt (D. 28.2.28.1).

64. Gaius, D. 1.7.2.1; Ulpian, Reg. 8.6.

65. Pomponius, D. 1.7.43 (Behrends [1995], S. 137). 
INDEX

Schlüsselwörter : Natur, Naturrecht, Kasuistik, Rom

Mots-clés : nature, droit naturel, casuistique, Rome

\section{AUTEURS}

\section{YAN THOMAS}

Yan Thomas (1943-2008) war ein herausragender Historiker des römischen Rechts. Nähere Informationen finden Sie hier. 